\title{
African Easterly Jet: Barotropic Instability, Waves, and Cyclogenesis
}

\author{
MAN-LI C. WU \\ Global Modeling and Assimilation Office, NASA Goddard Space Flight Center, Greenbelt, Maryland \\ ORESTE REALE* \\ Laboratory for Atmospheres, NASA Goddard Space Flight Center, Greenbelt, Maryland \\ SiEGFRIEd D. SchubERT AND MAX J. SuAREZ \\ Global Modeling and Assimilation Office, NASA Goddard Space Flight Center, Greenbelt, Maryland
}

CHRIS D. THORNCROFT

Department of Earth and Atmospheric Sciences, University at Albany, State University of New York, Albany, New York

(Manuscript received 7 December 2010, in final form 25 July 2011)

\begin{abstract}
This study investigates the structure of the African easterly jet, focusing on instability processes on a seasonal and subseasonal scale, with the goal of identifying features that could provide increased predictability of Atlantic tropical cyclogenesis. The Modern-Era Retrospective Analysis for Research and Applications (MERRA) is used as the main investigating tool. MERRA is compared with other reanalyses datasets from major operational centers around the world and was found to describe very effectively the circulation over the African monsoon region. In particular, a comparison with precipitation datasets from the Global Precipitation Climatology Project shows that MERRA realistically reproduces seasonal precipitation over that region. The verification of the generalized Kuo barotropic instability condition computed from seasonal means is found to have the interesting property of defining well the location where observed tropical storms are detected. This property does not appear to be an artifact of MERRA and is present also in the other adopted reanalysis datasets. Therefore, the fact that the areas where the mean flow is unstable seems to provide a more favorable environment for wave intensification, could be another factor to include - in addition to sea surface temperature, vertical shear, precipitation, the role of Saharan air, and others-among large-scale forcings affecting development and tropical cyclone frequency. In addition, two prominent modes of variability are found based on a spectral analysis that uses the Hilbert-Huang transform: a 2.5-6-day mode that corresponds well to the African easterly waves and also a 6-9-day mode that seems to be associated with tropicalextratropical interaction.
\end{abstract}

\section{Introduction}

This article investigates some large-scale properties of the atmospheric circulation over western Africa and the northern tropical Atlantic across seasonal and

* Additional affiliation: Goddard Earth Sciences Technology and Research, Universities Space Research Association, Columbia, Maryland.

Corresponding author address: Man-Li C. Wu, GMAO, NASA Goddard Space Flight Center, Greenbelt, MD 20771.

E-mail: man-li.c.wu@nasa.gov subseasonal time scales. In particular, relationships between instability of the atmospheric flow computed on a seasonal time scale, African easterly wave (AEW) activity, and the spatial distribution of tropical genesis points are investigated. The problem of tropical cyclogenesis can be studied from a variety of approaches, ranging from properties of the African easterly jet (AEJ) affecting wave development, intrinsic properties of the waves, mechanisms affecting the intensification of waves, to the actual occurrence of tropical cyclones (TCs). Notwithstanding the complexity of the tropical genesis and development problem and the prominent roles of vertical stability and precursor disturbances, it is widely 
accepted that sea surface temperatures and vertical shear (e.g., Shapiro and Goldenberg 1998; Aiyyer and Thorncroft 2006) are important factors conditioning the environment in which TC genesis and development may occur.

This article is centered on the development problem from a seasonal perspective. The possible properties and implications of the mean seasonal horizontal shear are explored. The research makes use of a synergistic approach involving spectral analysis, analysis of variance, composite analysis, and instability analysis. Empirical orthogonal functions and a spectral analysis based on the HilbertHuang transform (Huang et al. 1998, 1999) are used to separate purely tropical frequencies from modes that may represent some evidence of tropical-extratropical interaction. The article is a follow-up of a previous study (Wu et al. 2009a, hereafter WA09) on the AEJ structure and on the mechanisms contributing to its maintenance. In WA09 the current understanding of the AEJ structure was discussed as perceived through state-of-the-art reanalyses produced by operational centers such as the European Centre for Medium-Range Weather Forecasts (ECMWF), the National Centers for Environmental Prediction (NCEP), and the Japan Meteorological Agency (JMA). In addition, a set of experiments was performed to investigate the forcings contributing to the AEJ structure and position. WA09 results confirmed in part previous findings by Thorncroft and Blackburn (1999), on the importance of low-level heating in controlling the AEJ, and by Cook (1999), on the prominent role of soil moisture gradients. However, WA09 added new information by demonstrating that, rather than the soil moisture forcing alone, it is the combined effect of soil moisture, vegetation properties, and orography that controls the AEJ position and structure.

In this work, further research on the AEJ is presented, with a focus on mechanisms contributing to possible intensification of AEWs and to the spatial confinement of the TC genesis location points. The problem of TC formation over the eastern tropical Atlantic is very broad and can be split into at least two parts: AEW production and AEW development into TCs. In particular, the studies focused on AEW production tend to investigate either large-scale instability processes or the role of convection and the wave structure as wave-triggering mechanisms (e.g., Kiladis et al. 2006; Hall et al. 2006). For example, some of these studies focused on the role of heating profiles (e.g., Thorncroft et al. 2008), convection, and vorticity structure on a subsynoptic scale. Ferreira and Schubert (1997) demonstrated that convection in the intertropical convergence zone (ITCZ) can produce favorable conditions for larger-scale instabilities of the mean flow, even in absence of a jetlike energy source. There appears to be some agreement that shear instability alone cannot explain the initiation of AEWs (e.g., Hall et al. 2006; Hsieh and Cook 2008; Thorncroft et al. 2008). However, the studies focused on jet instability and those focused on the prominent role of convective precursors do not necessarily present opposing views. In fact, finite wave triggers and AEJ properties can work synergistically. For example, Leroux and Hall (2009) show how convectively triggered waves are influenced by intraseasonal variability of the AEJ. Mekonnen et al. (2006) attribute the origin of waves to convective precursors in the Darfur area, but suggest that the growth is supported by combined barotropic and baroclinic instability along the AEJ. Therefore, it is reasonable to reconcile all these views by stating that finite triggers still need an energy source; potential and kinetic energy of a jet, even if stable, can be converted into eddy kinetic energy of the waves.

Aiyyer and Thorncroft (2006) demonstrate that largescale vertical shear explains about $50 \%$ of the seasonal variability of tropical cyclones. Hopsch et al. (2007) investigate the relationship between West African disturbances and Atlantic TCs, finding a strong correlation between AEWs and TCs. As for the dominance of convective triggers over larger-scale mechanisms, Hopsch et al. (2007) suggest that "synoptic-scale AEWs can exist in the absence of convectively generated structures" but also that "coherent structures can exist in the absence of strong AEWs," thus reinforcing the idea that there is no contradiction between the two approaches. In summary, most studies seem to suggest that large-scale properties of the flow can cooperate with internal, convectively-driven, smaller-scale triggers by creating a more favorable environment for strengthening and further development.

The development of AEWs into tropical cyclones, through the creation of a closed circulation (e.g., Shapiro 1977), is the subsequent logical step and involves a variety of aspects depending on the scales of investigation. Sea surface temperature and vertical shear have long been considered as important environmental large-scale characteristics influencing tropical cyclone frequency, but many other factors, such as upper-tropospheric temperatures, stability, existence of precursor disturbances, and individual wave structures (Hopsch et al. 2010), are also relevant. In fact, even a hypothetical perfect knowledge of SST and vertical shear would not be sufficient to guarantee skillful tropical cyclone seasonal forecasts.

In this article, rather than focusing on the internal structure of individual waves and wave evolution, some additional large-scale properties of the flow across different time scales and the effects of planetary-scale forcings are investigated. As will be shown, the results do not contradict previous well-established findings on large-scale mechanisms relevant for cyclogenesis but, rather, add 
a new piece of information on the role of jet instability that may have implications for seasonal and subseasonal time-scale prediction capabilities.

The idea that some increase in tropical cyclone prediction skill, over the Pacific and Indian Oceans and on a subseasonal scale, could derive from an improved understanding of the Madden-Julian oscillation (MJO; Madden and Julian 1971, 1972) has been intensely investigated (e.g., Leroy and Wheeler 2008). This is not surprising, given its powerful impact on a variety of atmospheric events across weather and climate scales (e.g., Asnani 2005). This article does not examine the impact of the MJO directly; however, some of the results from previous studies of the MJO are relevant to this work and therefore need to be mentioned. In particular, Klotzbach (2010) discusses the relationship between Atlantic TC activity and the phase of the MJO (defined as in Wheeler and Hendon 2004) and provides one finding very relevant to this article: that the propagation and effects of the MJO over the African monsoon and the main development region (MDR) (Goldenberg and Shapiro 1996) seem to be strongly modified by the strength and sign of ENSO. Therefore, Klotzbach argues that the ENSO signal needs to be removed so as to correctly ascertain subseasonal variability in the Atlantic. Kossin et al. (2010) discuss the impact on tropical cyclone tracks caused by ENSO, the Atlantic meridional mode (AMM), the North Atlantic Oscillation (NAO), and the MJO, by utilizing a clustering technique previously applied to other basins. This provides a separation of four clusters of tracks, separated zonally and meridionally. The east-west separation corresponds to Gulf of Mexico versus Cape Verde systems, whereas the north-south clustering separates "purer" tropical systems from systems that display a higher degree of baroclinicity. The main impact of the MJO is found on the Gulf of Mexico systems.

While the MJO is not discussed in this study, Klotzbach's (2010) suggestion to remove the ENSO signal to better isolate subseasonal mechanisms was followed. The investigation is therefore focused only on ENSO neutral years.

A crucial tool for this work is the new Modern-Era Retrospective Analysis for Research and Applications (MERRA; Bosilovich et al. 2006, 2008) produced by the National Aeronautics and Space Administration Global Modeling and Assimilation Office (GMAO). The MERRA reanalysis is used to investigate the AEJ and is compared with reanalyses from other centers. Section 2 describes MERRA, the other datasets used for comparison, and the filtering methodology. Section 3 describes the climatology of the zonal wind and its gradients, and precipitation. Section 4 describes the results of a spectral analysis. Section 4 also provides an analysis of variance of some key fields that have been filtered in two time windows and discusses the implications of these results. Section 5 presents a dynamically based discussion and interpretation of the findings, and the conclusions.

\section{Data and methodology}

The MERRA dataset was produced by the GMAO with a focus on improving the historical analyses of the hydrological cycle on a broad range of weather and climate time scales. As such, it serves to place the NASA Earth Observing System (EOS) suite of satellite observations in a climate context. The data assimilation and forecasting system used to produce the MERRA data is the Goddard Earth Observing System model, version 5 (GEOS-5), documented extensively in Rienecker et al. (2008). In addition to the MERRA data, this study uses 1) the 40-yr ECMWF Re-Analysis (ERA-40; Uppala et al. 2005), produced for the period September 1957 to August 2002; 2) the NCEP/Department of Energy (NCEP-DOE) Global Reanalysis 2 (NCEP-R2; Kistler et al. 2001; Kanamitsu et al. 2002), which covers about 30 years; and 3) the Japanese 25-year Reanalysis (JRA-25; Onogi et al. 2007). In this work, however, only the data common to all of the reanalyses (1980-2001) are used. All means, unless otherwise stated, are computed for the 1980-2001 period.

It is important to note that the reanalyses differ in horizontal and vertical resolution. The NCEP-DOE data are at the lowest resolution: a triangular truncation at wavenumber 62 and 28 vertical levels (T62L28, corresponding to approximately $250-\mathrm{km}$ horizontal resolution, or $2.5^{\circ}$ ). The JRA-25 data are at T106L40, which corresponds to approximately $150 \mathrm{~km}$ (or about $1.5^{\circ}$ ) with 40 vertical levels. The ERA-40 data are truncated at T159L60, which produces a horizontal resolution of about $100 \mathrm{~km}\left(1.1^{\circ}\right)$ with 60 vertical levels. The MERRA products are at the highest resolution, $0.5^{\circ}$ latitude $\times$ $0.67^{\circ}$ longitude and 72 vertical levels. Only ERA-40 and MERRA have more than 20 levels in the stratosphere, which is the vertical sampling needed to depict certain aspects of stratospheric chemistry and dynamics. In particular, ERA-40 has approximately half of its 62 levels above the tropopause, whereas in MERRA more than 40 levels are above $200 \mathrm{hPa}$, thus having the most detailed depiction of the middle atmosphere.

In addition to the reanalyses, monthly merged precipitation analyses (version 2.1) of the Global Precipitation Climatology Project (GPCP; Adler et al. 2003) are used. These data are provided at $2.5^{\circ}$ horizontal resolution for the period 1979-present.

Filtering is performed using a symmetric, four-pole, lowpass, tangent Butterworth filter, described in Oppenheim 
and Schafer (1975), to isolate temporal scales from 2.5 to 6 and from 6 to 9 days. The particular choices of the time windows, as will be shown later, are guided by the result of a Hilbert spectral analysis, following previous work by Huang et al. (1998, 1999), Wu et al. (1999), Huang and Shen (2005), and Wu et al. (2009b). The HilbertHuang transform produces a joint distribution of timefrequency-energy called the Hilbert spectrum. The methodology, as discussed extensively in Huang et al. $(1998,1999)$, is adaptive, produces physically meaningful instantaneous frequencies as time differentials of the phase function, and is particularly suitable to analyze properties of nonstationary and nonlinear processes since it does not require any assumption about oscillatory processes, periodicities, or particular wave functions. This is an important difference with respect to other techniques that are typically adopted to infer periodic properties of atmospheric motions. The results of the spectral analysis, to be discussed in the next section, suggest that the commonly used time window of $2-10$ days can be divided into two subwindows, confirming previous findings by Diedhiou et al. (1998) and Diedhiou et al. (1999), but adding new information regarding the nature of the phenomena making up the two subwindows.

\section{Mean climatology}

In this section the zonal wind climatology for JulySeptember (JAS) based on MERRA is compared with that based on ERA-40, NCEP-R2, and JRA-25. We begin by reviewing the barotropic instability condition from Kuo (1949) in Fig. 1. The 700-hPa zonal wind $u(y)$, the local Coriolis parameter $f(y)$, and $-(\partial u / \partial y)$, which is the relative vorticity associated with meridional variations in $(u)$, are plotted as a function of latitude at $20^{\circ} \mathrm{W}$ against $f(y)-(\partial u / \partial y)$ and the quantity $K(y)=\partial / \partial y[f(y)-$ $(\partial u / \partial y)]$. Here $K(y)=0$ represents the generalized Kuo (1949) necessary condition for barotropic instability to occur. A change of sign of $K(y)$ on the cyclonic side of a flow indicates locations where barotropic instability is possible. If the flow is easterly, the condition favorable for barotropic instability in the Northern Hemisphere corresponds to a latitude $y_{\mathrm{cr}}$, where $K\left(y_{\mathrm{cr}}\right)=0$ and $K(y)>$ 0 for $y<y_{\mathrm{cr}}$ and $K(y)<0$ for $y>y_{\mathrm{cr}}$. In the particular case of Fig. 1, the critical latitude $y_{\mathrm{cr}}$ is at $13^{\circ} \mathrm{N}$-that is the latitude at which the sum of the local Coriolis parameter and the relative vorticity is maximum. Small variations of $K(y)$, on the order of $\left(10^{-11} \mathrm{~m}^{-1} \mathrm{~s}^{-1}\right)$ south or north of the critical latitude, correspond to very small variations of $f(y)-(\partial u / \partial y)$, which appears flat around the latitude at which $K(y)=0$. According to the Kuo theory, it is important to recall that the most unstable modes occur for longer wavelengths than that of the neutral wave, and
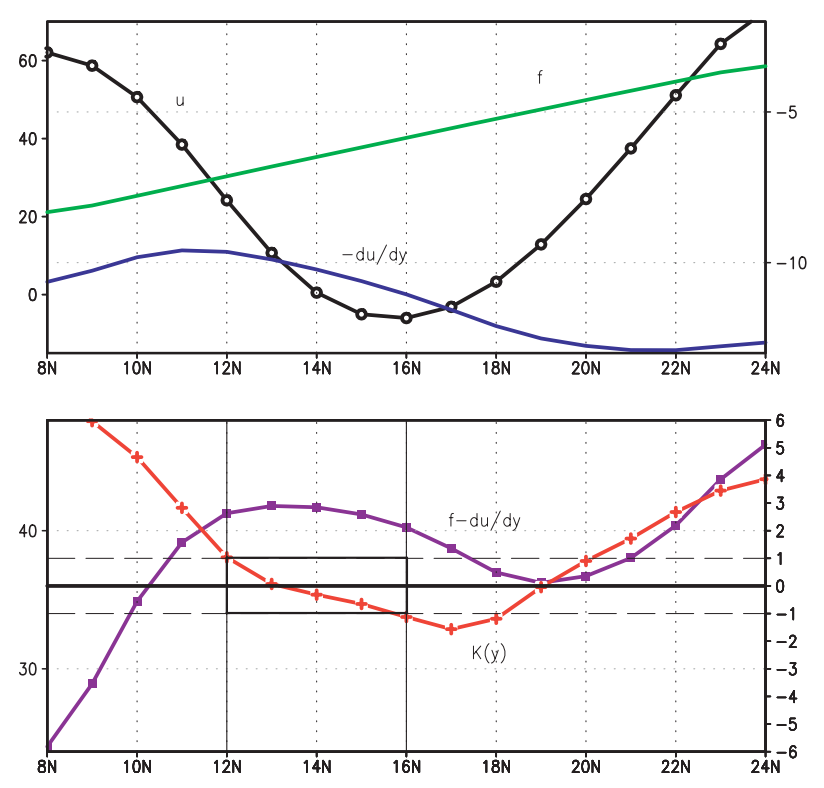

FIG. 1. (top) JAS 1980-2001 700-hPa zonal wind climatology ( $\mathrm{m} \mathrm{s}^{-1}$, black line, right ordinate axis), and $f(y)\left(\mathrm{s}^{-1}\right.$, green, line) and $-\partial u / \partial y\left(10^{-6} \mathrm{~s}^{-1}\right.$, blue line), both referring to the left ordinate axis. (bottom) $K(y),\left(10^{-11} \mathrm{~m}^{-1} \mathrm{~s}^{-1}\right.$, red line, right ordinate axis) and $f(y)-\partial u / \partial y\left(10^{-6} \mathrm{~s}^{-1}\right.$, purple line, left ordinate axis). All quantities computed from MERRA data.

longer waves are more likely where the zonal flow is stronger. This translates, with respect to the latitude interval $12^{\circ}-16^{\circ}$ in Fig. 1 , that the more unstable waves are likely to be closer to the zonal flow maximum [with slightly negative values of $K(y)$ ], rather than between $12^{\circ}$ and $13^{\circ}$ [where $K(y) \geq 0$ ]. In the following figures, the previously discussed quantities are plotted together with the zonal wind so as to better understand the three-dimensional structure of the AEJ and its stability properties.

In Fig. 2, the zonal wind climatology for JAS based on MERRA is compared with that based on ERA-40, NCEP-R2, and JRA-25. The well-known structure of the AEJ and of the regional circulation can be distinguished in the four sets of reanalyses: in particular, a jet maximum $z 11 \mathrm{~m} \mathrm{~s}^{-1}$ is located at $600 \mathrm{hPa}$ at $\sim 15^{\circ} \mathrm{N}$ over western Africa. As noted previously in WA09, the structure of the analyzed African easterly jet (AEJ) differs slightly on the eastern side, with NCEP-2 extending it more to the east with respect to the others, and JRA-25 having the lower speeds over eastern Africa, and overall representing the weakest AEJ. The eastward extension of the AEJ, and its weakness, particularly over data-sparse areas such as the Ethiopian highlands, may be relevant to the development of AEWs in model forecasts (Agusti-Panareda et al. 2010). Among various minor discrepancies in the representation of the AEJ, it is noted that the ERA-40 and the NCEP-R2 products depict two distinct maxima in the AEJ (unlike MERRA, which exhibits one stronger elongated 


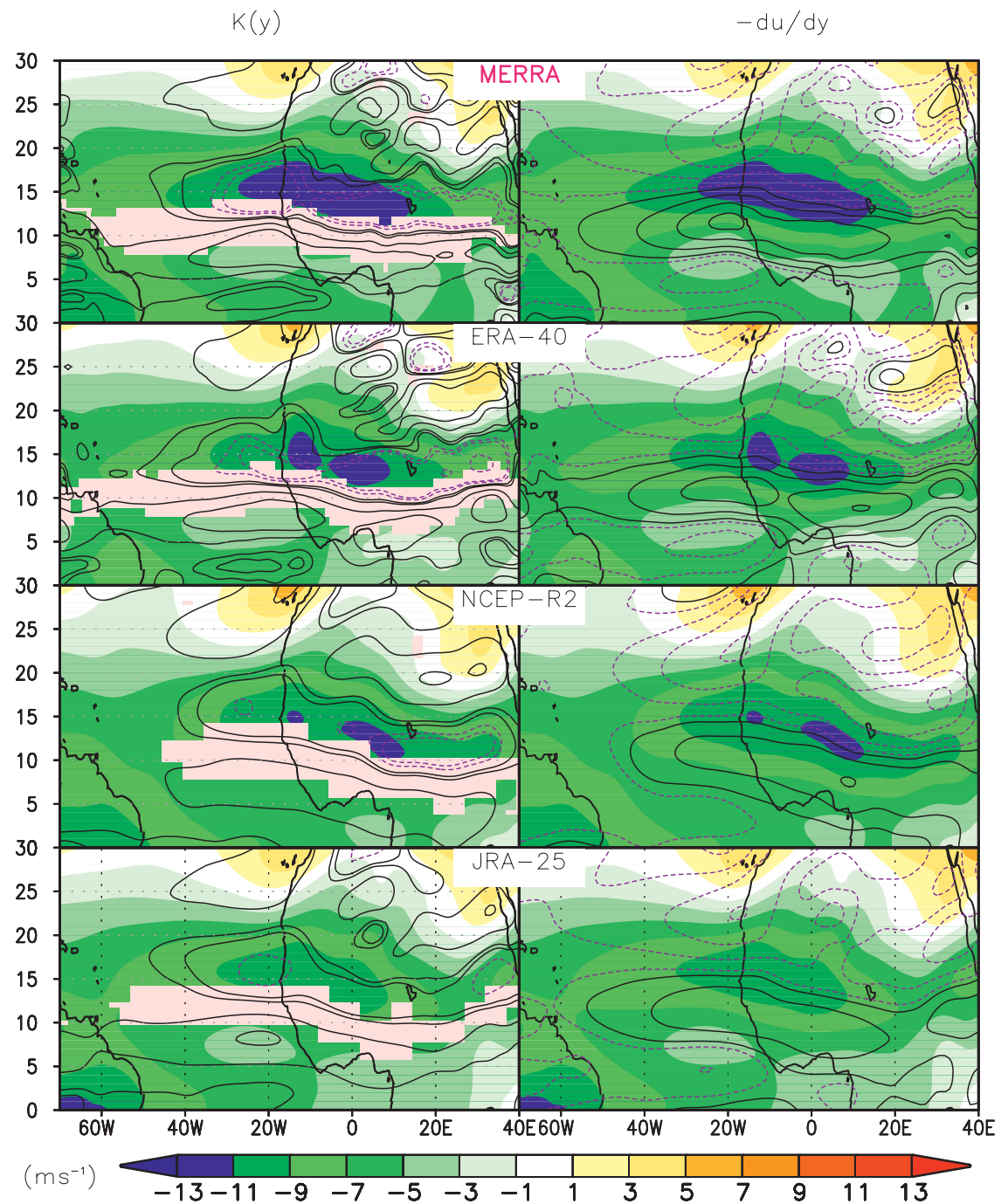

FIG. 2. JAS zonal wind climatology of the AEJ ( $\mathrm{m} \mathrm{s}^{-1}$, shaded, 1980-2001) at $600 \mathrm{hPa}$ based on MERRA, ERA-40, NCEP-R2, and JRA-25: (left) $K(y)\left(10^{-11} \mathrm{~m}^{-1} \mathrm{~s}^{-1}\right.$, contours at $\pm .5,1$, $2,3,5)$ and (right) $-\partial u / \partial y\left(10^{-6} \mathrm{~s}^{-1}\right.$, contours at $\left.\pm 1,5,10,15,20\right)$. The areas where vorticity is positive are shaded in light pink in the left column.

maximum), and the AEJ representation in MERRA and the ERA-40 extends more to the west than in the other two datasets. As pointed out in WA09, it cannot be argued, in the absence of a denser observational network (e.g., Parker et al. 2008), which of these representations of the AEJ is more realistic. The need for additional observations to further improve the representation of the AEJ, especially on its eastern side, has been stressed by many authors (e.g., Agusti-Panareda et al. 2010).

The different representations of velocity gradients in the four datasets are of greater interest than the simple assessment of the AEJ extension. Therefore, Fig. 2 also shows the zonal wind structure with respect to the horizontal shear produced by the zonal component $(u)$ of the wind. In particular, $-(\partial u / \partial y)$ and $K(y)$ are superimposed.
As mentioned previously, the change of sign from $K(y)>$ 0 to $K(y)<0$ with increasing latitude is particularly meaningful. Here we consider the range of values between $-10^{-11}$ and $10^{-11} \mathrm{~m}^{-1} \mathrm{~s}^{-1}$ to be sufficiently close to zero. So, $|K|<10^{-11} \mathrm{~m}^{-1} \mathrm{~s}^{-1}$ delineates the area where the mean zonal component of the flow is unstable, provided that $K(y)$ is positive (negative) to the south (north) of it. The left panels in Fig. 2 show (in pink) the areas where the vorticity induced by the zonal flow is cyclonic. The oceanic part of this region, constrained by $K$ being sufficiently small and the vorticity being positive, is also the area where most of the storm genesis points are observed, as will be shown later. It should be noted that, as shown by Hsieh and Cook (2008), the cyclonic shear side of the AEJ is mainly established in 
association with moist convection. At the same time, there is also horizontal shear in the absence of moist convection [as seen in the dry convection runs of Thorncroft and Blackburn (1999)]. However, it is not possible to estimate the percentage contribution coming from the moist convection. In fact, at the resolution of all reanalyses used, including MERRA, convection is not resolved but parameterized. Therefore, the effects of convection are somewhat taken into account and may be manifest in a modification of the wind field and, thus, vorticity itself, but it is not possible to separate the two. We expect that the higher-resolution analyses may have much higher values of vorticity associated with shear, large-scale convective systems, and the overall representation of tropical weather systems.

Despite the differences in resolution, all reanalyses (though less evident in NCEP-R2) show an area of negative $K$ values at about $15^{\circ} \mathrm{N}, 20^{\circ}-30^{\circ} \mathrm{W}$, which is the eastern edge of the main development region (MDR). The significance of this finding arises from the fact that, in general, one would regard the instability properties of the African easterly jet to be relevant only at a specific time, arising out of a combination of instantaneous barotropic and baroclinic instabilities, as shown by Hsieh and Cook (2008) and previously discussed by Thorncroft and Hoskins (1994a,b). In contrast, the quantities involved in Fig. 2, such as $K(y)$, are computed as a time mean for the season.

These also reflect the presence of both barotropic and baroclinic instability [in fact, $K(y)<0$ is mostly at the core of the AEJ, which corresponds to higher vertical shear in the levels below, in turn corresponding to strong meridional surface temperature gradients], but the significance arises from the fact that they represent a mean condition computed through several months.

It is known that many environmental factors such as sea surface temperatures, surface temperature gradients, moisture and precipitation on various scales, contributions from Saharan air, and cold air intrusions from the Mediterranean across the Sahara can all inhibit or enhance the development of AEWs into cyclones.

Nonetheless, the fact that something as simple as the barotropic instability of the mean flow, without considering any other property, appears to coincide broadly with the area where a large number of storms tend to occur (on the eastern border of the MDR), is important. The possible underlying reason is that, where the AEJ is seasonally more unstable, there could be a higher probability that waves become more intense, and these in turn have a higher chance of producing tropical cyclones. Therefore, the magnitude and spatial extent of the region where vorticity is positive and $K(y)$ changes sign may influence the amplitude of the AEW activity. This conjuncture will be further supported later. Again, without downplaying the importance of the many other factors that can affect tropical cyclogenesis, it is possible that the mean instability of the flow offers an additional constraint. If true, this would offer some potential for seasonal predictability, in that the mean flow is likely more predictable on a seasonal time scale than its higher frequency fluctuations.

As previously mentioned, Fig. 2 shows some differences between the reanalyses, including in the analyzed AEJ and its gradients (in particular, these are stronger in MERRA than in the NCEP-R2 and JRA-25). On the other hand, the gradients and horizontal structure of the $K(y)$ function at $600 \mathrm{hPa}$ appear quite comparable in ERA-40 and MERRA, indicating that the AEJ is more unstable in these datasets than in NCEP-R2 or JRA-25. It is also worth noting that JRA-25 provides the least unstable representation of the AEJ, particularly on its eastern side. These discrepancies could be partly caused by resolution differences as well as by differences in the assimilation systems and model parameterizations.

As seen in Fig. 2, the stronger values of the meridional shear of the zonal wind are concentrated in a strip to the south of the AEJ. In this area, both the easterly wind (increasing with latitude) and low-level westerly monsoonal flow (decreasing with latitude) contribute to the meridional horizontal shear. To further clarify this aspect, the vertical structure of the wind and its gradients is illustrated in Figs. 3 and 4. In these figures, the corresponding meridional cross sections of zonal wind, $K(y)$, and meridional shear are plotted at $0^{\circ}$ and $20^{\circ} \mathrm{W}$ to investigate the differences between land and ocean. All cross sections confirm the fundamental features of the AEJ and surrounding circulation consisting of a lowlevel westerly flow confined below $800 \mathrm{hPa}$, a low-level easterly flow (Harmattan) confined between $20^{\circ}$ and $30^{\circ} \mathrm{N}$, and an upper-level easterly flow [tropical easterly jet (TEJ)] at latitudes south of $10^{\circ} \mathrm{N}$.

Figure 3 emphasizes those heights and latitudes that are more barotropically unstable at $0^{\circ}$ longitude. All four datasets agree that the strongest cyclonic shear associated with the AEJ is centered at about $600 \mathrm{hPa}$ slightly south of about $15^{\circ} \mathrm{N}$. However, the cross sections emphasize a different slope of the maximum shear values, which is even more evident in the $K(y)$ plots. It is only MERRA and ERA-40 that display a clear "column" of negative $K$ values stretching from 900 to $500 \mathrm{hPa}$ at about $10^{\circ}-15^{\circ} \mathrm{N}$, indicating that the jet is less baroclinic in the other two reanalyses.

Figure 4 shows the same meridional vertical cross section at $20^{\circ} \mathrm{W}$, which intersects the region of interest completely over the ocean. The AEJ core is slightly to the north of $15^{\circ} \mathrm{N}$ in all reanalyses. Moreover, as in the 


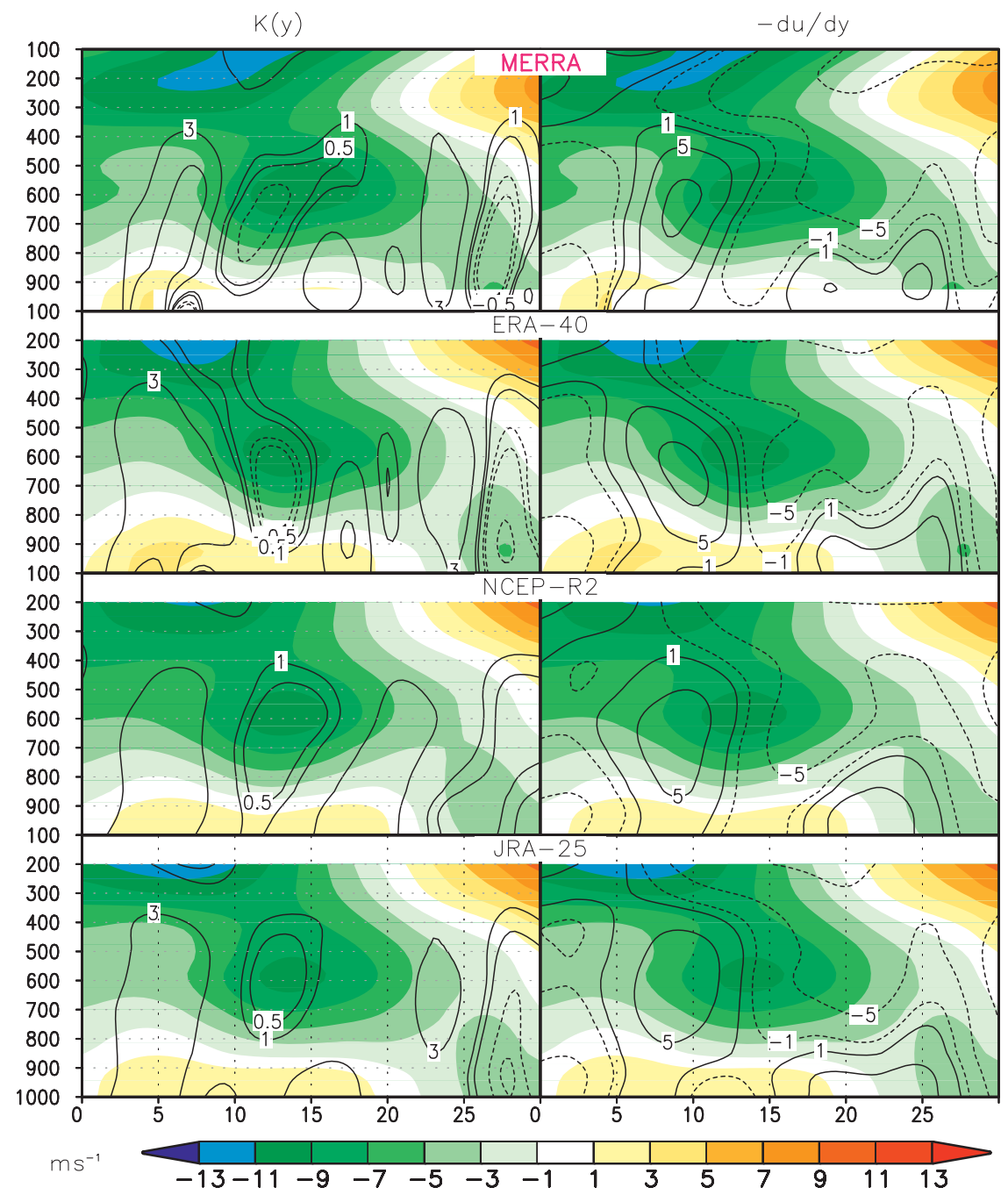

FIG. 3. Vertical meridional cross section at $0^{\circ}$ of JAS zonal wind climatology of the AEJ $\left(\mathrm{m} \mathrm{s}^{-1}\right.$, shaded, 1980-2001) based on MERRA, ERA-40, NCEP-R2, and JRA-25: (left) $K(y)$ $\left(10^{-11} \mathrm{~m}^{-1} \mathrm{~s}^{-1}\right.$, contours at $\left.\pm .5,1,2,3,5\right)$ and (right) $-\partial u / \partial y\left(10^{-6} \mathrm{~s}^{-1}\right.$, contours at $\pm 1,5$, $10,15,20)$.

previous cross section taken at $0^{\circ}$ longitude, there is overall agreement between the reanalyses on the lowlevel westerly flow confined below $800 \mathrm{hPa}$ and affecting the latitude band between the equator and $20^{\circ}$, the lowlevel Harmattan flow confined between $20^{\circ}$ and $30^{\circ} \mathrm{N}$, and the upper-level easterly flow (TEJ) at latitudes south of $10^{\circ} \mathrm{N}$, with the MERRA data providing the stronger values. As seen in Fig. 3, ERA-40 and MERRA are consistent in depicting the cyclonically sheared (southern) flank of the AEJ as barotropically unstable, with values of $K(y)$ decreasing with increasing latitude and with a column of near-zero $K(y)$. In all reanalyses the vorticity structure appears more vertically aligned than in Fig. 3, and the cyclonic vorticity maximum to the south of the jet level is also substantially stronger than at $0^{\circ}$. The implication is that the formation of a vertically aligned, barotropically unstable column seems to become even more likely as one moves from land $\left(0^{\circ}\right)$ toward the ocean $\left(20^{\circ} \mathrm{W}\right)$. This is interesting because some developing waves tend to show vertically aligned structures at these levels when still over land, before transitioning from land to ocean, and even more so after transition since surface baroclinicity weakens over the ocean. The idea that waves grow out of a combination of baroclinic and barotropic instabilities over land, but that barotropic growth prevails over the ocean, is supported by several studies (e.g., Arnault and Roux 2009). While the development of African easterly waves (AEWs) into tropical cyclones may occur as a result of other contributing mechanisms, the fact that the mean seasonal flow displays some vertical alignment, 


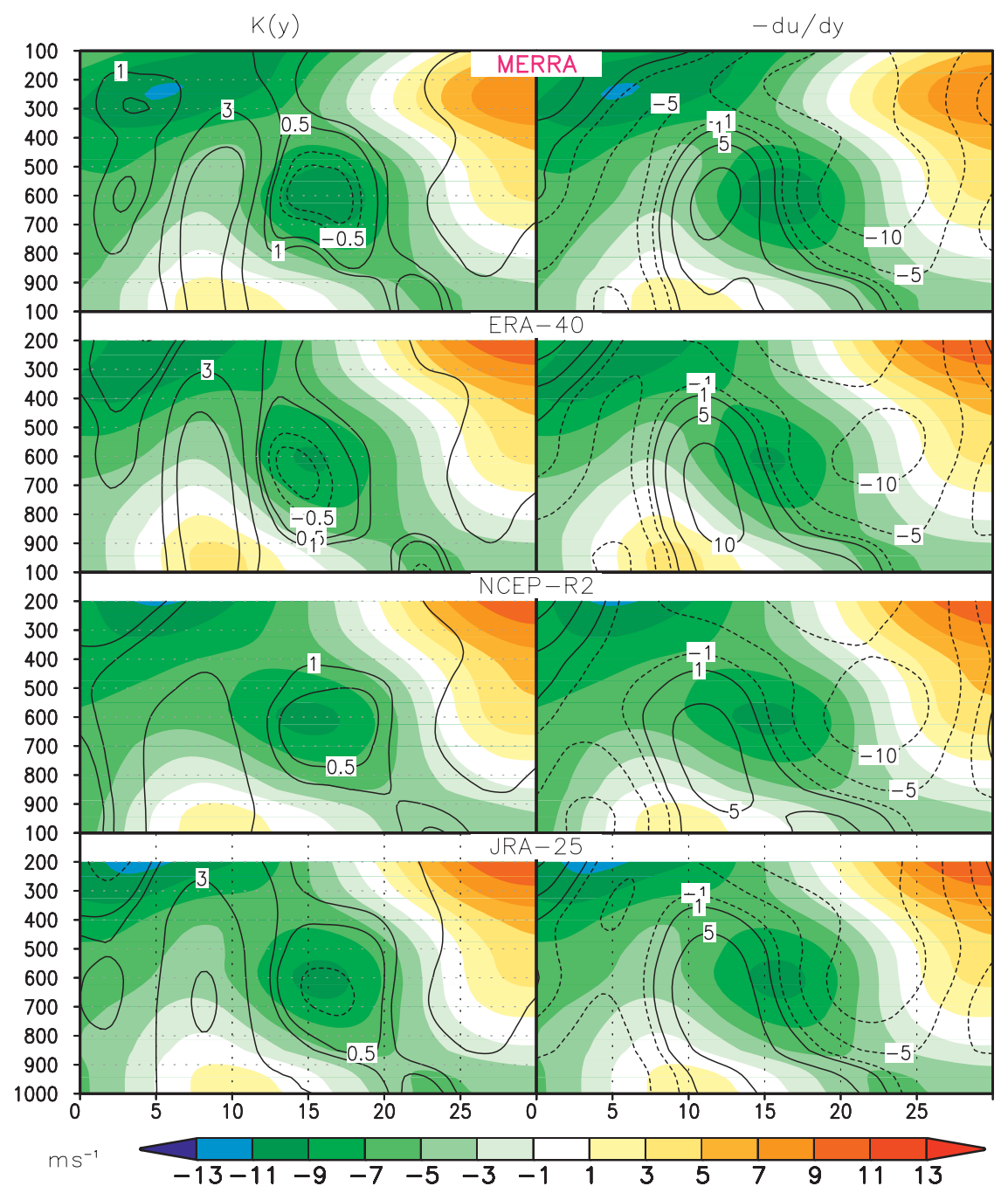

FIG. 4. Vertical meridional cross section at $20^{\circ} \mathrm{W}$ of JAS zonal wind climatology $\left(\mathrm{m} \mathrm{s}^{-1}\right.$, shaded, 1980-2001) based on MERRA, ERA-40, NCEP-R2, and JRA-25: (left) $K(y)\left(10^{-11}\right.$ $\mathrm{m}^{-1} \mathrm{~s}^{-1}$, contours at $\left.\pm 5,1,2,3,5\right)$ and (right) $-\partial u / \partial y\left(10^{-6} \mathrm{~s}^{-1}\right.$, contours at $\left.\pm 1,5,10,15,20\right)$.

which increases by moving from land to ocean, would suggest that a connection may exist between some instability properties of the seasonal flow and the individual systems. In other words, we are noting that mean properties of the flow seem to agree with requirements of individual systems. This reinforces the notion that a more unstable mean flow, more vertically aligned, is indicative of a probability that individual systems may find a more favorable environment for development, an idea that needs further analysis and testing.

It can be argued that the mean JAS climatological conditions do not reproduce a true "background" state but rather, in diluted form, features that are observed often on weather time scales and instantaneous fieldsin other words, the signatures of weather systems. As will be shown later, by comparing the locations where observed tropical cyclogenesis verifies, it seems that those areas where the mean flow satisfies the condition for barotropic instability on a seasonal time scale are also the areas where actual storms cluster. At this time a connection cannot be strictly demonstrated, but it is worth mentioning that Hopsch et al. (2010) also note a tendency of genesis points to cluster toward the coastal area and attribute the clustering of coastal developments to increased vorticity induced by rainfall over the Guinea highlands. Moreover, it will be shown later that the accumulated energy of the waves (as in Done et al. 2010) corresponds very well with the areas appearing more barotropically unstable in the seasonal mean.

Figure 5 shows the precipitation climatology together with the departures from the GPCP datasets. As is to be expected with the larger uncertainties typical of 


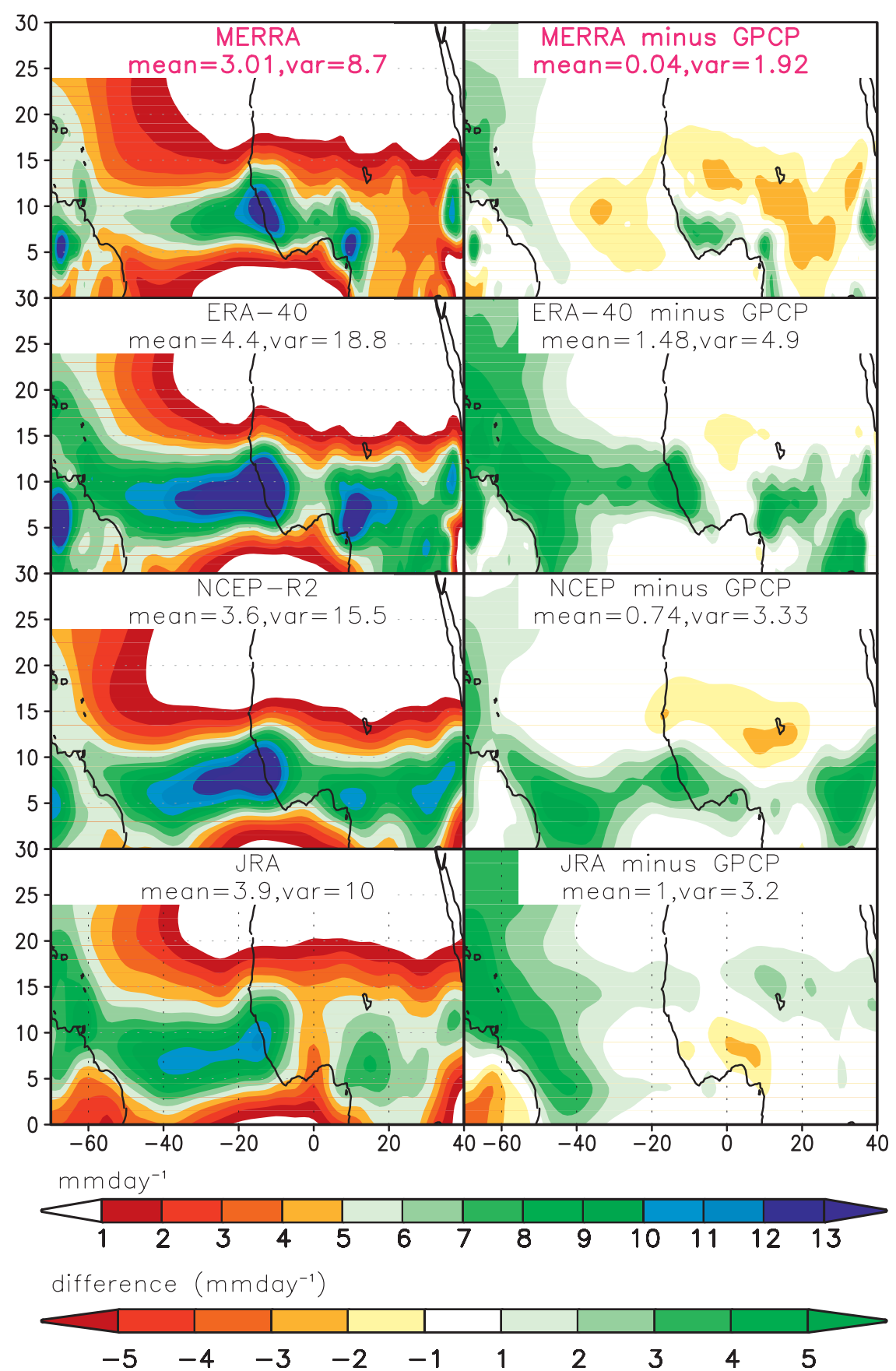

FIG. 5. (left) JAS precipitation ( $\mathrm{mm} \mathrm{day}^{-1}$, top color bar) and (right) departure from the GPCP (bottom color bar).

precipitation fields, the differences between the reanalyses are large, with ERA-40 and NCEP-R2 having a wet bias on the southern side of the ITCZ, MERRA having a dry bias on the northern side of the ITCZ and to the east, and JRA-25 having a wet bias over the Sahel and a dry bias over the Guinea coast. In terms of absolute differences, it should be noted that the MERRA dataset has the overall smallest departure from GPCP: less than $3 \mathrm{~mm}$ day $^{-1}$ over most areas and a mean departure of only 0.04 against $1.48,0.74$, and $1.0 \mathrm{~mm}_{\text {day }}{ }^{-1}$ for ERA-40, NCEP-R2, and JRA-25, respectively. However, MERRA has the largest dry bias over the east, which may indicate, according to Thorncroft et al. (2008), a lower number of AEWs being triggered. Figure 5 also 

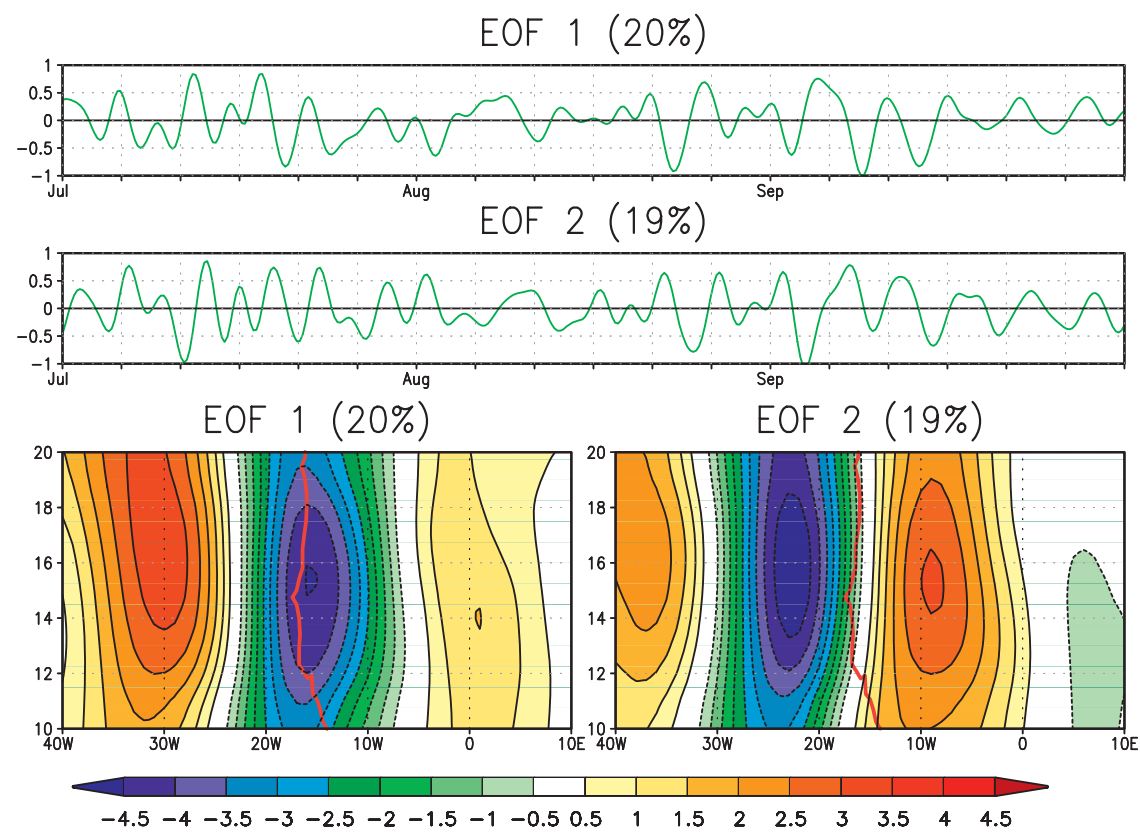

FIG. 6. First and second EOFs of the meridional component of the 700-hPa wind, computed during JAS, in neutral ENSO years, from $10^{\circ}$ to $20^{\circ} \mathrm{N}, 40^{\circ} \mathrm{W}$ to $10^{\circ} \mathrm{E}$, based on MERRA.

shows the variance of the interannual precipitation departures from the JAS GPCP mean for all four reanalyses during the 1980-2001 period. It can be noted that the variance of the departures from GPCP is smallest for MERRA (1.92, with the largest being 4.9 for ERA-40).

\section{Spectral analysis and analysis of variance}

Following Klotzbach (2010) the analysis is limited to ENSO neutral years. We begin the analysis of variance by performing the EOFs of the meridional component of the 700-hPa wind. The EOFs are computed from data that has been filtered to retain the scales of 2.5-90 days on a domain ranging from $10^{\circ}$ to $20^{\circ} \mathrm{N}, 40^{\circ} \mathrm{W}$ to $10^{\circ} \mathrm{E}$ : zonal changes in the domain within the same latitude range do not show major impacts on the EOF structure (not shown). Figure 6 shows the first two principal components (PCs) resulting from this analysis, which account for about $40 \%$ of the total variance. The two EOFs are in quadrature and explain a comparable amount of variance, thus providing a representation of propagating easterly waves. The third and fourth EOFs each account for an additional $11 \%$ of the variance (not shown), so the first four components explain about $62 \%$ of the total variance.

A number of Hilbert-Huang spectra were computed for the first four PCs over the entire domain and various subdomains. Figures 7 and 8 show the Hilbert transform of the first and second EOFs for the entire domain in which the EOFs in Fig. 6 were computed. The frequencies at which peaks of spectral density occur are an indication of physically meaningful instantaneous periodicities (Huang et al. 1998, 1999), suggesting dominant time scales of atmospheric motion. The results from these calculations hinted at an interesting property: time scales greater and less than 6 days appeared to be separated in the first two EOFs (with two peaks at about 6.5 and 5 days, respectively) but not in the third and fourth EOFs (not shown). In addition, spectra computed on different subdomains seemed to suggest that the two time scales of atmospheric motion, separated by the 6-day period in the first two EOFs, appear to dominate in different locations (as will be discussed later) with the time scale less than 6 days confined to the lower latitudes and the time scale greater than 6 days more prominent in the subtropics (not shown).

Based on these preliminary assessments, and to substantiate this aspect further, the Hilbert-Huang spectra are shown for two locations-north and south of the AEJ axis at $12^{\circ} \mathrm{N}$ and $17^{\circ} \mathrm{W}$ and $26^{\circ} \mathrm{N}$ and $5^{\circ} \mathrm{W}$ - and compared with the corresponding Fourier analyses. These locations are chosen because of their representativeness: the former refers to a point slightly south of the AEJ core, immediately off the west coast of Africa, and the latter refers to a point north of the AEJ, over land. In Fig. 9 the Hilbert-Huang and Fourier spectra for the meridional component of the $700-\mathrm{hPa}$ wind are presented, for the point at $12^{\circ} \mathrm{N}, 17^{\circ} \mathrm{W}$. The abscissa indicates frequency in terms of the number of cycles over the length in days $n$ of the JAS period, whereas the ordinate indicates spectral density. 


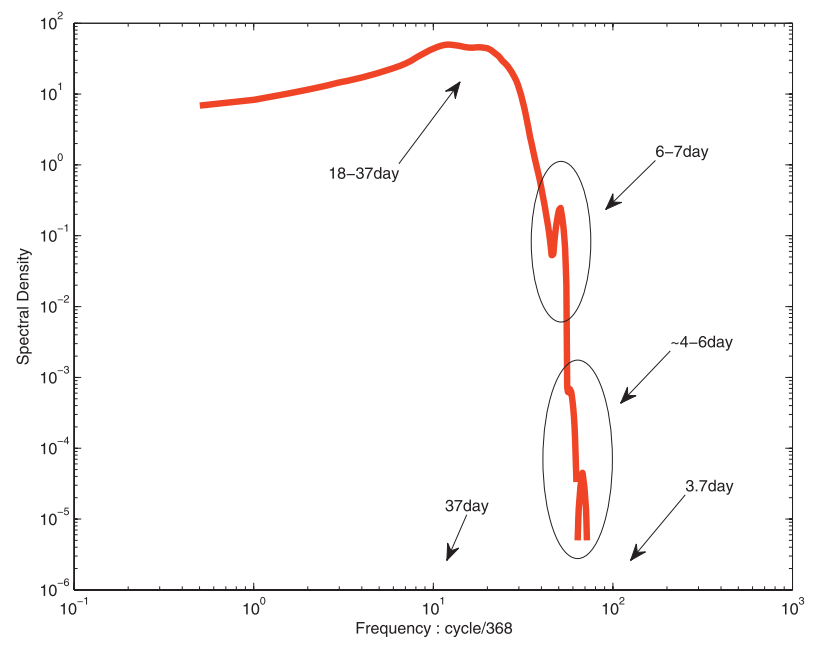

FIG. 7. Hilbert-Huang spectra based on MERRA meridional $700-\mathrm{hPa}$ wind (total domain, from $40^{\circ} \mathrm{W}$ to $10^{\circ} \mathrm{E}$ and $10^{\circ} \mathrm{N}$ ) for $\mathrm{EOF}$ 1 (JAS, 1980-2001).

Unlike the spectral analysis previously computed on the EOFs, in Fig. 9 the Hilbert-Huang transform is performed on the full field. A prominent sharp maximum at $\sim 10^{1.9} 1 / n$ (about 5 days), between two minima that approximately correspond to periods of 2.5 and 6 days, indicates the most prevalent frequency of AEWs

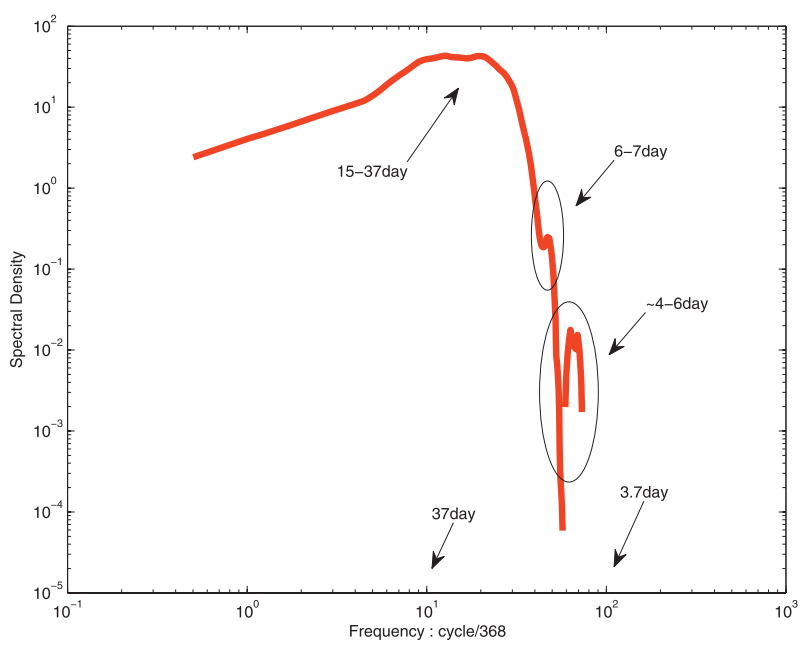

FIG. 8. As in Fig. 7 but for EOF 2.

according to the Hilbert-Huang spectral analysis. Another, less sharp and broader, maximum at $\sim 10^{1.1} 1 / n$ indicates an oscillatory mode of about two or three weeks, which appears westward propagating (not shown), and therefore different from the quasi-stationary mode observed by Mounier et al. (2008) but similar to the periodicity of 10-30 days discussed by Janicot et al.
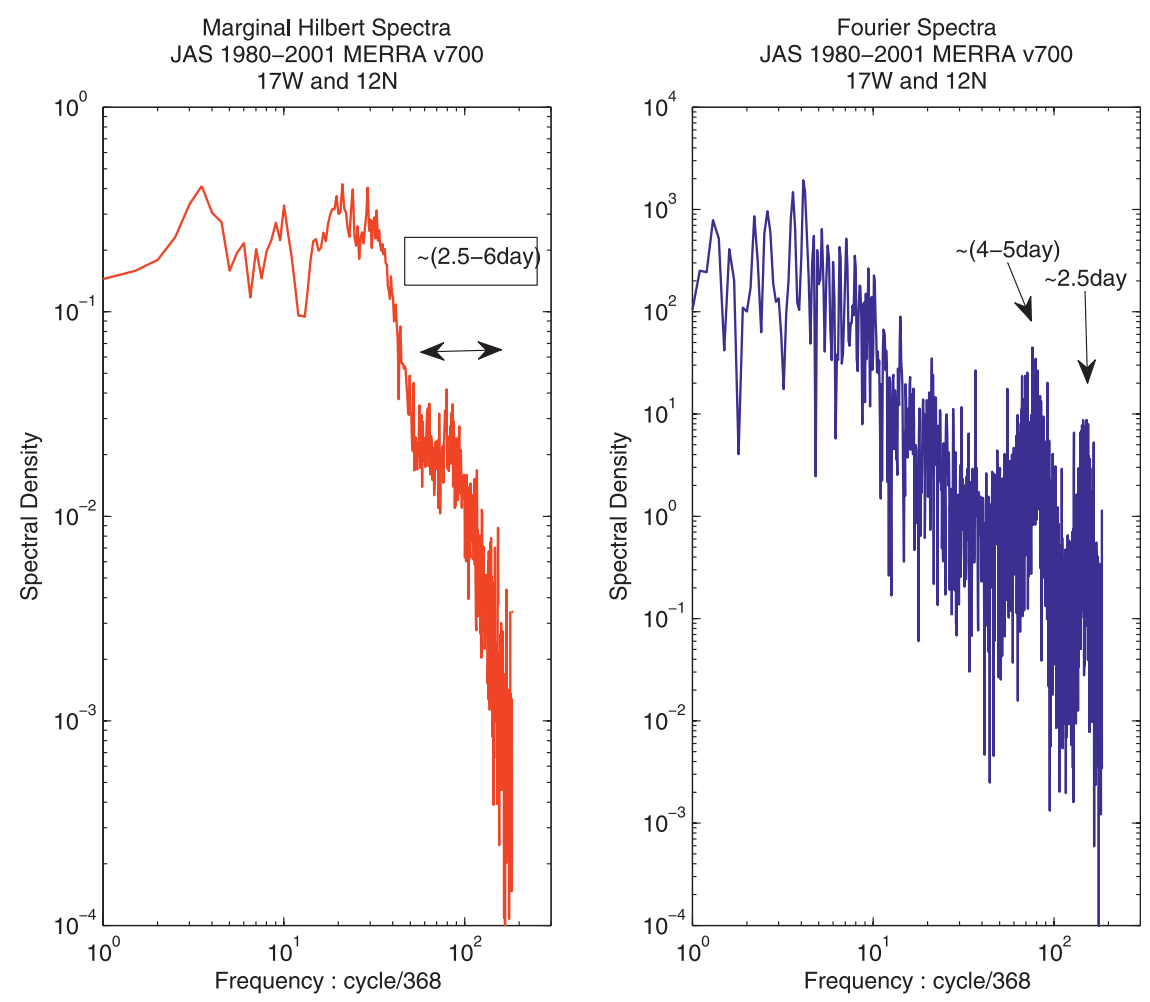

FIG. 9. Hilbert-Huang (left) and Fourier (right) spectra based on MERRA meridional 700-hPa wind (full field) at one single point $\left(12^{\circ} \mathrm{N}, 17^{\circ} \mathrm{W}\right.$; JAS, 1980-2001). 

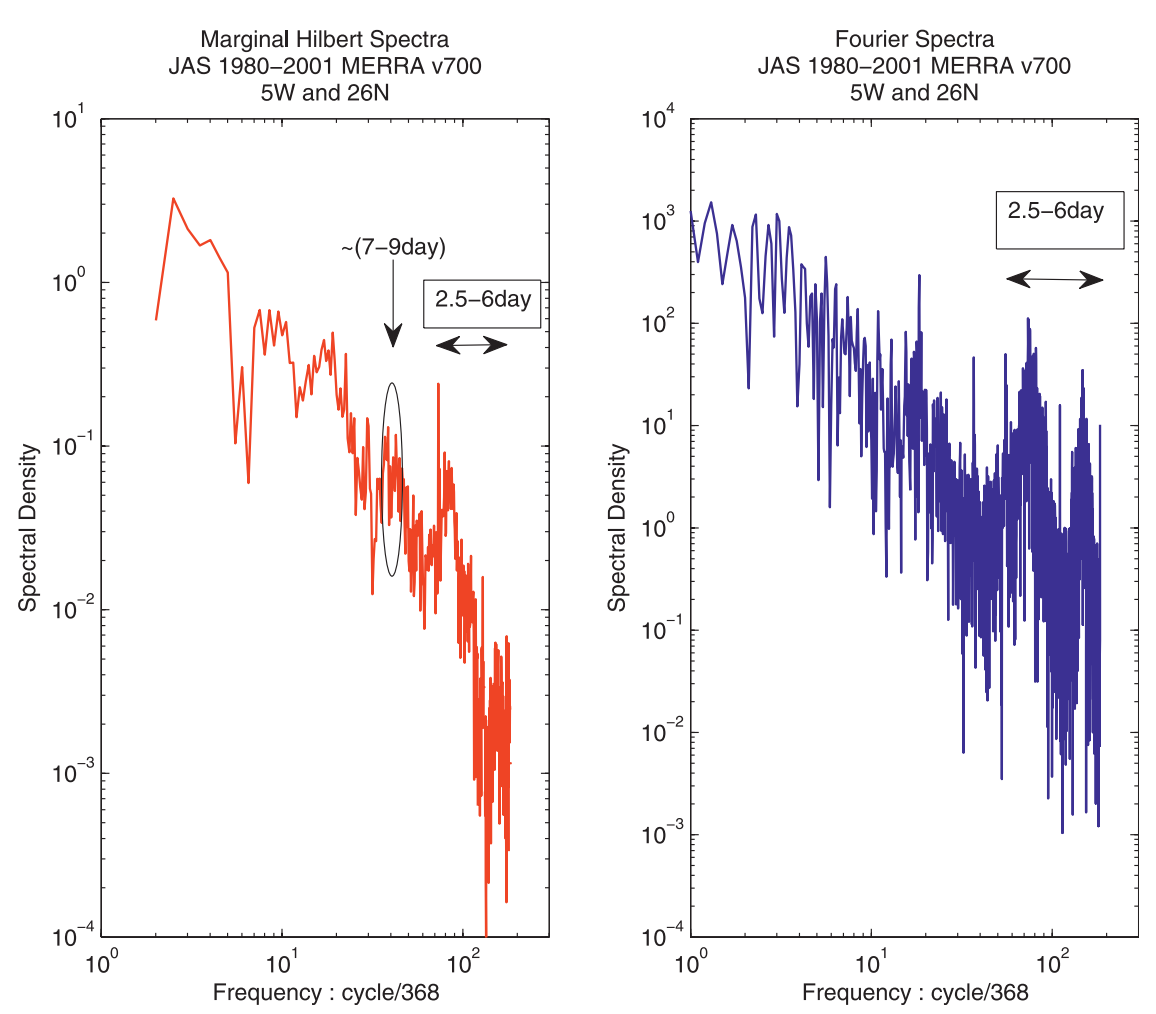

FIG. 10. As in Fig. 9 but for one single point at $26^{\circ} \mathrm{N}, 5^{\circ} \mathrm{W}$.

(2010). Other time scales greater than a month are also present but are not central to this article.

Figure 10 is the same as Fig. 9 except the HilbertHuang spectra are computed for a location over the Sahara, to the north of the AEJ and more to the east at $26^{\circ} \mathrm{N}, 5^{\circ} \mathrm{W}$. Spectra computed for locations at the same latitude but on the ocean $\left(20^{\circ} \mathrm{W}\right)$ are very similar (not shown). In the Hilbert-Huang spectra, there is clear evidence of the same maximum at $\sim 10^{1.9} 1 / n$ confined by the time scale of 2.5-6 days but also of another maximum at $\sim 10^{1.3} 1 / n$, which is the center of the 6-9-day window. This maximum does not appear in the Fourier spectrum. It is important to emphasize that the Hilbert-Huang transform does not need any assumption on specific sinusoidal functions as the Fourier transform, and as such it is more likely to represent physically meaningful time scales. Since in this dataset the 6-9-day mode appears undetected when performing Fourier analysis, it is possible that the preferred use of a Fourier transform by several authors has been one of the reasons why the 6-9-day time scale has received less attention. However, African waves with time scales of 6-9 days were observed and studied by De Felice et al. $(1990,1993)$ and previously by Yanai and Murakami (1970), who performed spectral analyses of equatorial waves and noted westward propagating disturbances over northern Africa with periods of about a week. As will be discussed later in section 5, the 2.5-6-day frequency range appears to be connected with AEWs whereas, in the 69-day frequency range, African waves seem to be produced by interactions of tropical disturbances with midlatitude variability. Possible causes for this variability on this time scale will be discussed later in this section and in section 5 .

Since this study is mostly focused on the seasonalmean instability properties of the AEJ and its possible link to weather systems, the variance of the meridional component of the wind is used to assess AEW activity (Fig. 11). Large convective systems are also associated with increased variance of the wind. However, considering the resolution of reanalyses and their inability to resolve convective systems, it is likely that the wind variance reflects predominantly AEW activity. The most interesting element in Fig. 11 is the overlap between the areas of maximum fraction of total variance and the areas where $K(y)$ is close to zero (within the interval $\pm 10^{-11} \mathrm{~m}^{-1} \mathrm{~s}^{-1}$ ). The maximum variance more to the north is associated with areas where $K(y)<$ 0 (recall Fig. 2) and with baroclinic instability. As stated before, $K(y)$ is computed from the JAS average, and the $K(y)$ transition from positive (to the south) to negative values (to the north) represents the area where disturbances are more likely to extract kinetic energy from the mean zonal flow by barotropic growth, in 


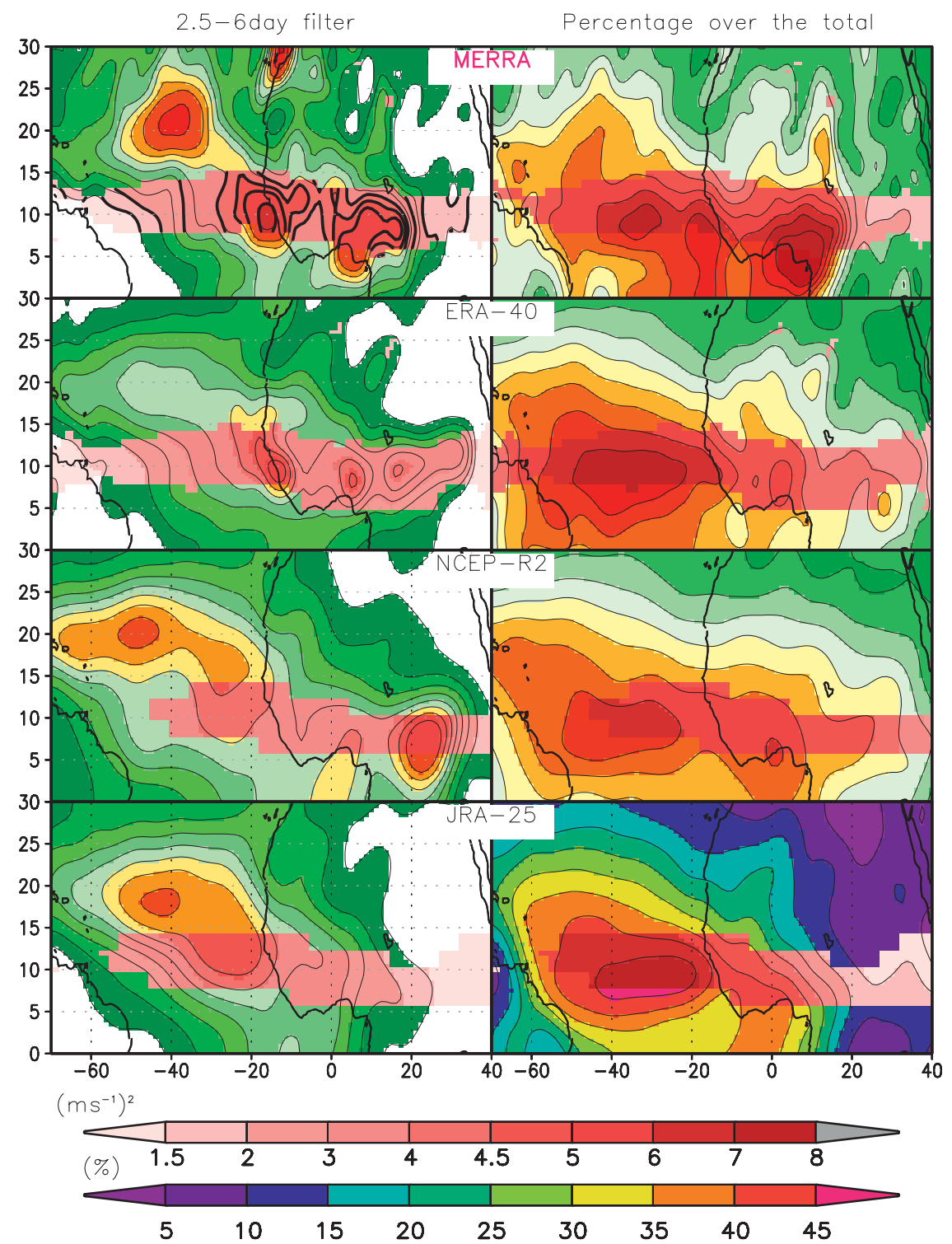

FIG. 11. Variance of the 6-hourly meridional component of the wind, bandpass filtered through a (left) 2.5-6-day passband $\left(\mathrm{m}^{2} \mathrm{~s}^{-2}\right.$, upper color bar) and (right) fraction (\%) of the total (lower color bar). Shading indicates the area where the necessary condition for barotropic instability, computed as in Fig. 1 (with $K$ in the range $\pm 10^{-11}$ ), is satisfied.

addition to the combined effect of baroclinic growth caused by negative potential vorticity gradients in the jet core [dominated by $K(y)<0$ ] and positive surface temperature gradients that are strong over land.

This area coincides well with the areas where the $2.5-$ 6-day variance of the meridional wind (indicative of actual wave activity) is maximum. This suggests that instability properties of the mean flow are connected with instabilities occurring in the instantaneous flow. As previously stated, the mean flow should not necessarily be interpreted as a background flow because the signatures of individual waves contribute to the mean. But, the forecasting implications exist regardless of the causal relationship between seasonal mean and individual wave. In fact, if substantiated by further results, this could provide an important diagnostic tool to assess the potential for AEW development and tropical cyclone genesis within seasonal forecast runs. It is important to stress that no obvious correspondence between seasonal means of large-scale fields and occurrence of individual storms has been found in other basins such as the Indian Ocean, for example, where storm genesis and development is extremely erratic. On the contrary, it appears that Atlantic tropical cyclogenesis has a higher degree of constraint than other 


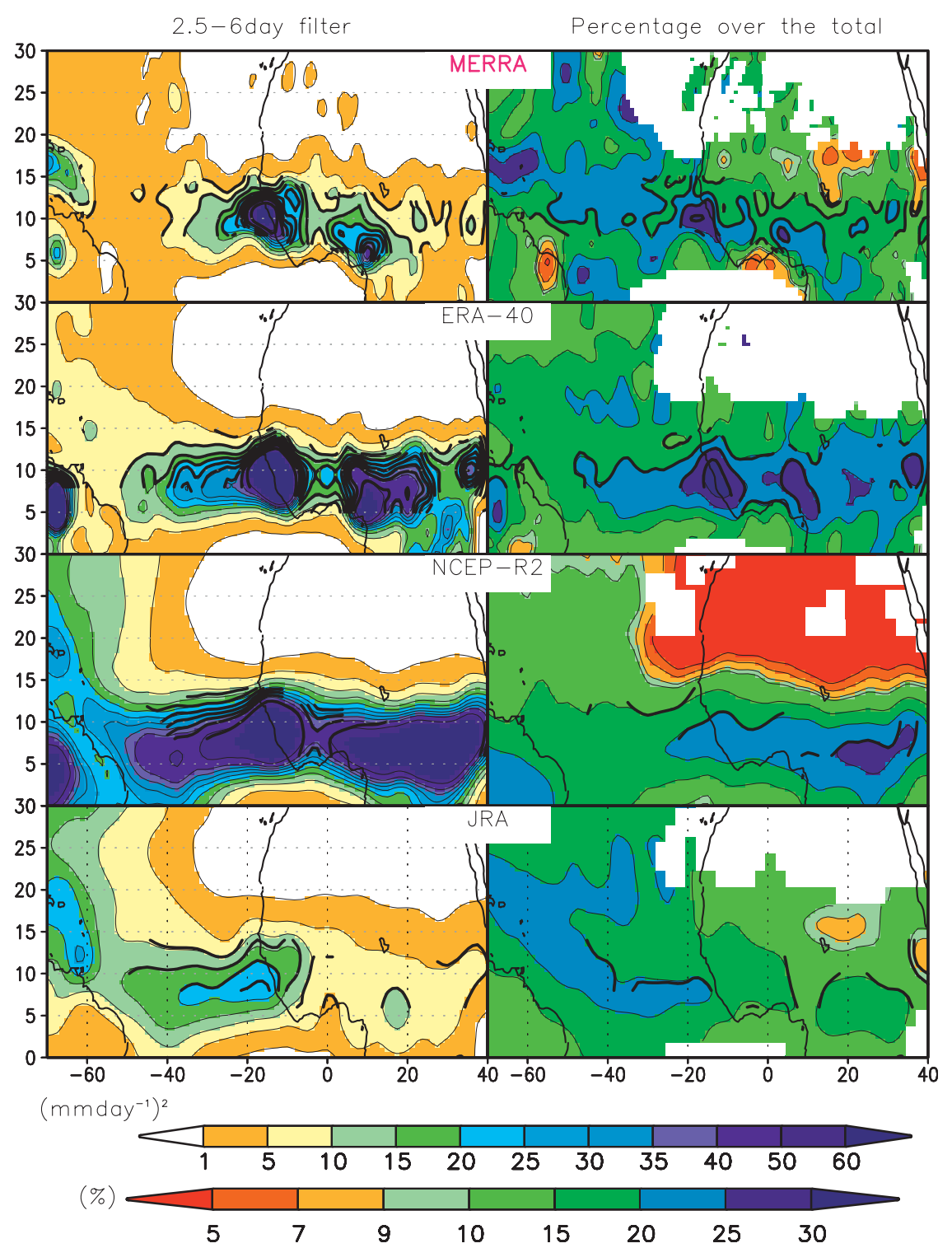

FIG. 12. Variance of 6-hourly precipitation, bandpass filtered through a (left) 2.5-6-day passband $\left(\mathrm{mm}^{2} \mathrm{~d}^{-2}\right.$, top color bar) and (right) fraction (\%) of the total (bottom color bar).

basins and, as such, may offer larger room for predictability at seasonal time scales.

In Fig. 12, the same plot is produced from precipitation datasets to further support the above point. The 2.56-day bandpass-filtered precipitation south of the AEJ is a strong indicator of wave activity and/or enhanced convection. This is not surprising since latent heat plays an important role in the AEW amplitude. While acknowledging differences between reanalyses (in particular, MERRA and ERA-40 highlight topographic features more than the other two), it should be noted that a good correspondence exists between the maximum filtered precipitation variance and the areas that, in Fig. 11, display a correspondence between variance of meridional wind and areas where the mean flow satisfies the barotropic instability condition [and of baroclinic instability where $K(y)<0]$ on a seasonal time scale.

In Fig. 13, the 2.5-6-day bandpass filtered variance of the zonal and meridional wind components-computed from MERRA at 500, 600, 700, 850, and $925 \mathrm{hPa}-$ emphasizes the three-dimensional structure of the variance and also shows the levels that are more active on this time scale. The variance of the zonal component has a distinct maximum at about $10^{\circ}-15^{\circ} \mathrm{N}$ and $600 \mathrm{hPa}$, whereas the variance of the meridional component is stronger at about $10^{\circ}-20^{\circ} \mathrm{N}$ and $925 \mathrm{hPa}$, with the higher values more 


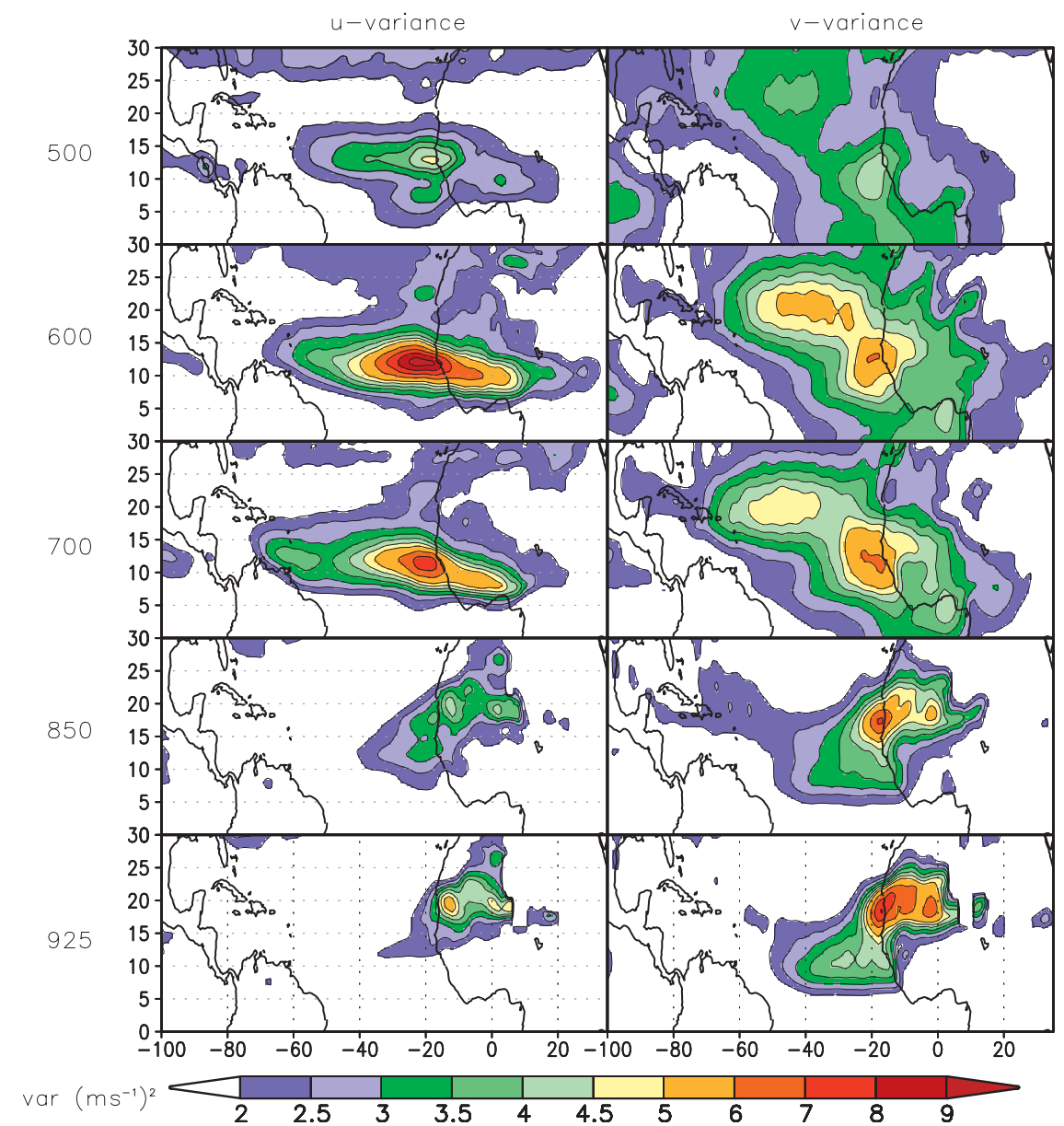

FIG. 13. Variance of (left) 6-hourly zonal $u$ (top color bar) and (right) meridional $v$ (bottom color bar) wind, bandpass filtered through a 2.5-6-day passband $\left(\mathrm{m}^{2} \mathrm{~s}^{-2}\right)$, from MERRA analyses.

to the north. The low-level variance of the meridional component may reflect two types of phenomena, developing to the north and south of the $15^{\circ} \mathrm{N}$ latitude, respectively. At about or south of $15^{\circ} \mathrm{N}$, stronger values right at the transition from coast to ocean suggest that, in the reanalyses fields, disturbances originating at the AEJ level (evident in the zonal fields in Fig. 13) reach the coastline and trigger more intense convection, thus enhancing the meridional component of the flow in the lower levels. This is in agreement with the downward development described by Hopsch et al. (2010). However, the peak in the variance of the meridional component at $925 \mathrm{hPa}$, north of $15^{\circ} \mathrm{N}$, is consistent with the contribution to wave growth caused by surface baroclinicity and to vortices developing on a more northern track.

It is important to stress that this is not an artifact of the particular assimilation and forecast system adopted: the exact same result, notwithstanding minimal internal differences, is also obtained by computing the same quantities from the ERA-40, NCEP-2, and JRA-25 reanalyses (not shown). In fact, all four reanalyses show, over the ocean, a maximum of the 2.5-6-day filtered variance of the zonal wind component at $600 \mathrm{hPa}$ and a maximum of the 2.5-6-day filtered variance of the meridional wind component at $925 \mathrm{hPa}$. This is an indication of a fundamental property of the flow and its tendency to produce, or strengthen, disturbances that grow both barotropically and baroclinically. However, over land, JRA-25 shows much less variance, consistent with the overall weaker AEJ shown in Fig. 2 and with the lower resolution.

Figure 14 shows the same fields as in Fig. 13, except that the winds are filtered to retain 6-9-day time scales. The intent of this figure is to shed some light on the spatial distribution of this time scale and to ascertain whether it is purely tropical or results from the interaction with higher latitudes. The figure shows that the 6-9-day time scales of motion do not produce a strong signal in the 


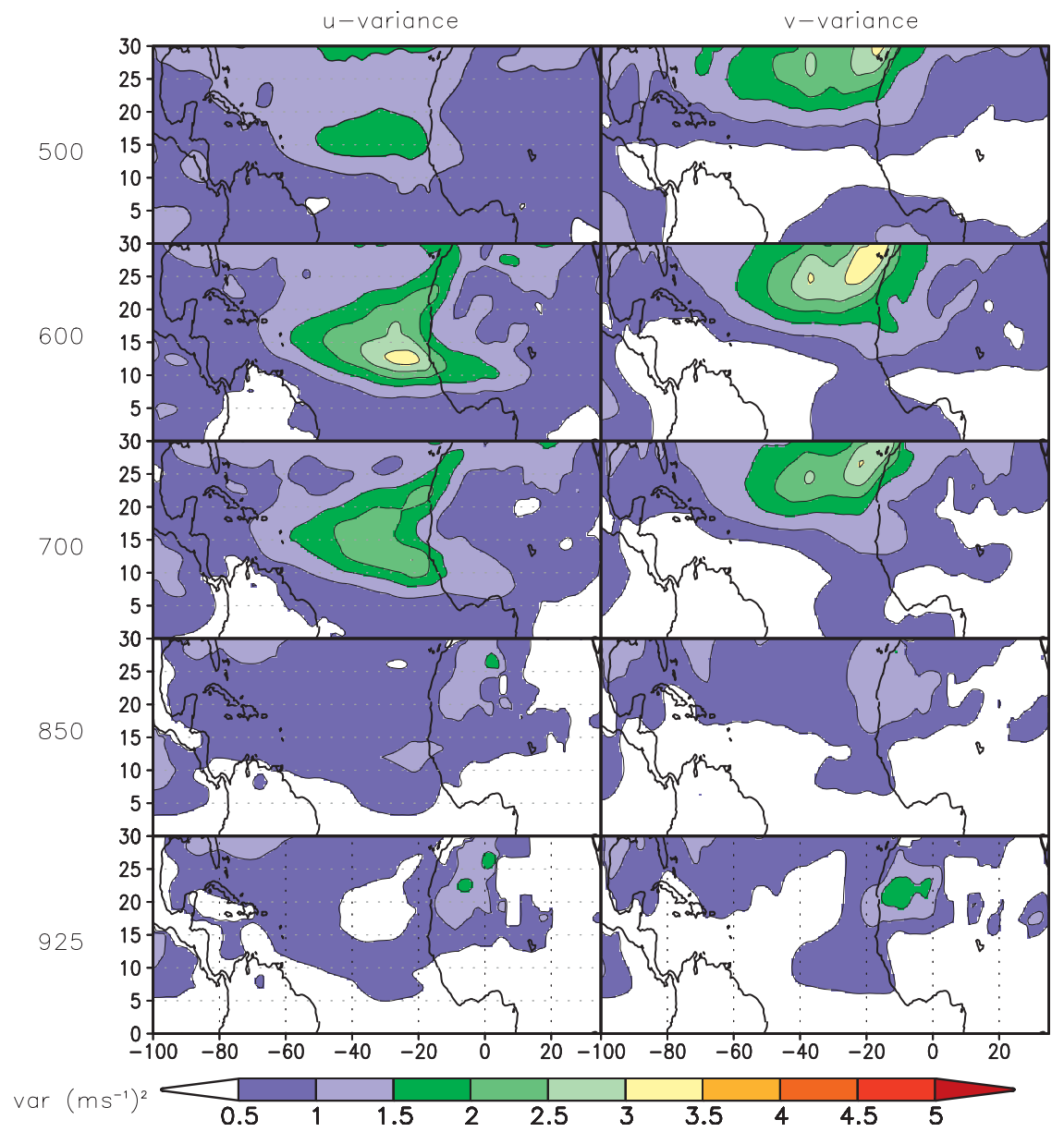

FIG. 14. As in Fig. 13 but bandpass filtered through a 6-9-day passband.

lower latitudes and lower levels. On the contrary, most of the signal of the 6-9-day zonal wind is at $600-700 \mathrm{hPa}$, with a shape that strongly resembles the typical track of early recurving disturbances. For the bandpass filtered meridional component, there is a maximum only north of $20^{\circ} \mathrm{N}$ at levels higher than $700 \mathrm{hPa}$, including $500 \mathrm{hPa}$. The shape of this maximum is surprisingly similar to the common "plumes" of moisture advected by a predominantly southwesterly flow, which are often seen in water vapor channels stretching from the Atlantic ITCZ toward the northeastern Atlantic or the Mediterranean region (e.g., Turato et al. 2004).

As stated before, time scales of 6-9 days, based on single point observations, were noted and documented by De Felice et al. $(1990,1993)$. However, not being able to reproduce this as a global equatorial mode in a theoretical modeling framework, the authors concluded that the monsoonal signal might hide the signal in the Pacific and Indian Oceans (De Felice et al. 1993). However, Diedhiou et al. $(1998,1999)$ confirm the presence of the 6-9-day time scale but note that it appears at a more northern latitude, it is less intense in June-July, and attribute it to periodic strengthening of subtropical anticyclonic cells. In this study, we suggest an explanation for the 6-9-day time scale different from that of De Felice et al. (1990, 1993), involving an interaction with extratropical dynamics and more in line with the findings by Diedhiou et al. (1998, 1999). In particular, we suggest that the 6-9-day filtered variance may indicate a tropicalextratropical interaction between midlatitude and tropical activity. Several different types of weather events could be manifestations of this interaction.

For example, tropical systems that recurve earlier and turn into northward or eastward motion, or the southernmost edge of fronts connected with the midlatitude activity. These are connected because a relaxation of the high pressure belt at about $20^{\circ}-30^{\circ} \mathrm{N}$ often allows the southern edge of fronts to penetrate farther south and, at the same time, drive southerly flow ahead of such cold fronts away from the deep tropics into the midlatitudes. Disturbances originating from AEWs can frequently be advected northward in such flow at various levels of 
development. These can be either simple convective clusters that end up feeding the warm sector of midlatitude cyclones or developed tropical systems commonly known as "early recurvers" that are steered by a midlevel southwesterly flow. Contributions of moist tropical air following trajectories very similar to the patterns shown in Fig. 14 have been found to be significant for floods in the Mediterranean region (e.g., Reale et al. 2001; Turato et al. 2004; Krichak et al. 2004).

To further emphasize the physical foundation of separating the spectrum into the two subscales, Fig. 15 shows the variance of the 700-hPa meridional component of the wind filtered through 2.5-9-day, 2.5-6-day, and 6-9-day passband. There is a clear spatial separation between the two subwindows, with the 6-9-day variance mostly confined to latitudes higher than $20^{\circ} \mathrm{N}$. An almost identical result is obtained when plotting the same quantities from ERA-40, NCEP-R2, and JRA-25 (not shown), suggesting a robust physical foundation for the idea that two separate time scales seem to be present over the region. At the same time, the variance peak in the 2.5-6-day passband at about $20^{\circ} \mathrm{N}$, weaker than the main peak confined at about $10^{\circ}-15^{\circ} \mathrm{N}, 20^{\circ} \mathrm{W}$, supports the idea that the amplitude of the 2.5-6-day time scale weakens with increase in latitude, in agreement with the Hopsch et al. (2007) findings.

Figure 16 shows the lag-correlation coefficient computed between the 700-hPa zonal and meridional components of the wind at one location $\left(26^{\circ} \mathrm{N}, 20^{\circ} \mathrm{W}\right)$ and all of the surrounding points at lag intervals of one day. The figure illustrates what appears to be a mode propagating with a time scale of about seven days, centered in the transitional zone between the deep tropics and extratropics. It appears to be a physically based motion structure, like a Rossby wave type of event, based upon the interaction between midlatitude activity and tropical dynamics. That the ITCZ periodically breaks and reforms and that pulses of enhanced and reduced organized convection unrelated to AEW activity are observed in that latitude range is known to operational weather forecasting in the tropical Atlantic: with this work it is suggested that this is more than chaotic variability, but that it may be the result of the interaction between midlatitude activity and tropical dynamics. Over the African monsoon region and the tropical Atlantic, cold air outbreaks are observed on a regular basis (e.g., Vizy and Cook 2009) in the form of cold surges associated with short-wave trough passages over the Mediterranean Sea. These cold surges enhance convection over northern and western Africa but reduce it over the eastern Sahel. It is possible that the particular topography of northern Africa and the Mediterranean Sea favors some tropical-extratropical

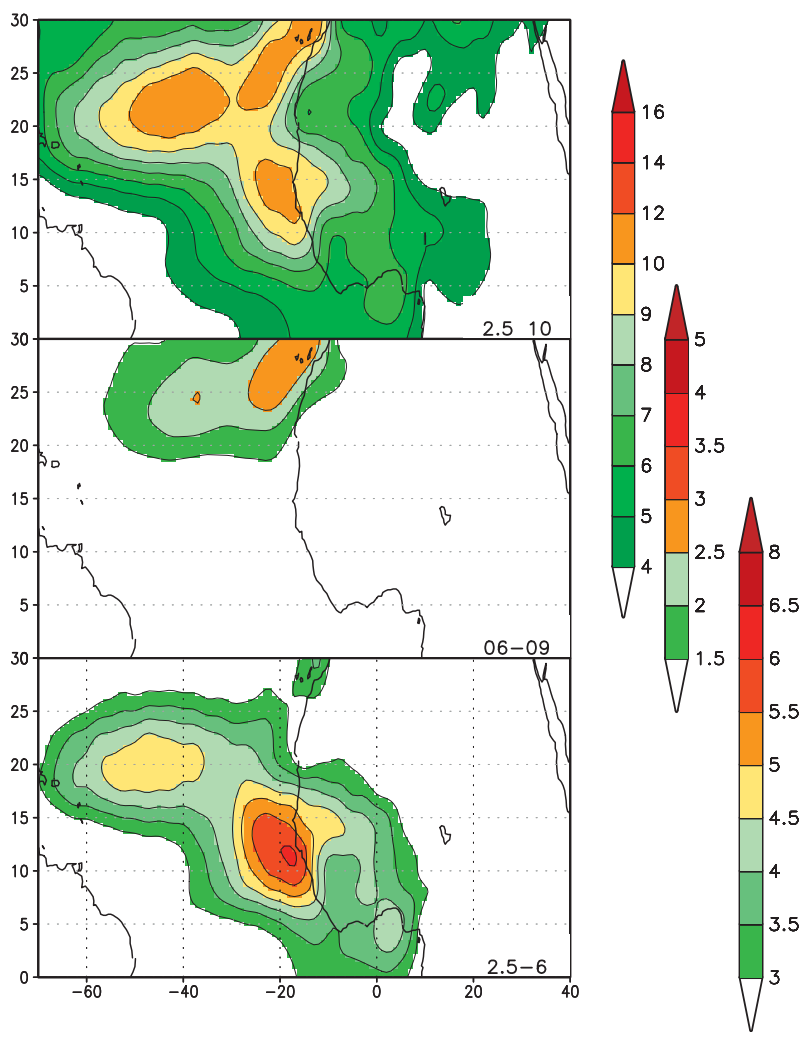

FIG. 15. Variance of (top) hourly meridional wind (left color bar) filtered through a (top) 2.5-9-day (left color bar), (middle) 6-9-day (middle color bar), and (right) 2.5-6-day (right color bar) passband $\left(\mathrm{m}^{2} \mathrm{~s}^{-2}\right)$, from MERRA analyses.

interaction with a well-defined time scale and that this interaction is captured by the Hilbert-Huang analysis. This periodicity is different from the longer time scales studied by Janicot et al. (2010) and it bears more similarity to the one observed by Diedhiou et al. (1999). Overall, it appears to be a little-known phenomenon that can potentially affect the way in which AEWs and midlatitude troughs interact.

We then substantiate the importance of 1) stratifying the analysis of the dynamics on the region according to the ENSO sign and 2) emphasizing the physical meaningfulness of both the 2.5-6-day bandpass filtered 700-hPa variance of the meridional wind and the low values of mean $K(y)$. The need for filtering out the ENSO signal to better understand the circulation over the region was emphasized by several authors including Klotzbach (2010). In this article we focus on ENSO neutral years. Since the AEJ properties are different in positive and negative ENSO years (not shown here), a treatment of the behavior of the AEJ in response to the ENSO signal will be the subject of a following article.

The possibility of a connection between mean instability properties of the seasonal flow as a condition 


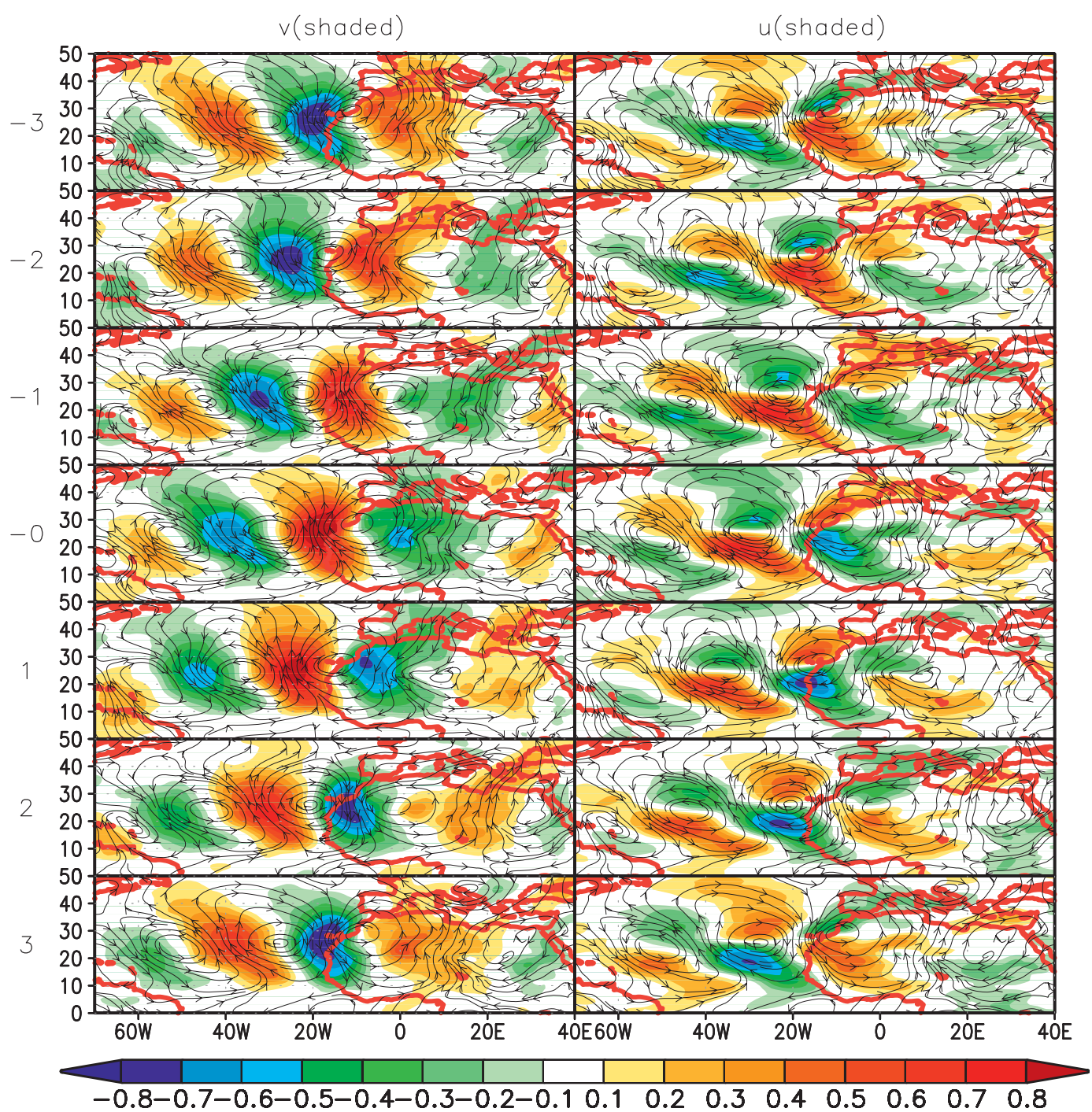

FIG. 16. Lag correlation coefficient of the 700-hPa (left) meridional $v$ and (right) zonal wind $u$ computed at $26^{\circ} \mathrm{N}$, $20^{\circ} \mathrm{W}$ (shaded) and streamlines of total wind, filtered through a 6-9 day passband, from MERRA analyses.

favoring the occurrence of more intense waves is discussed with the aid of Fig. 17 in which the mean AEJ, the values of $K(y)$, and the AEW intensity are shown together. The accumulated square of vorticity for the period is the adopted metric to infer AEW intensity, similar to Done et al. (2010). The areas where the most intense waves occur, or where there is greater likelihood of AEW activity, correspond quite well to the area where the mean values of $K(y)$ are closer to zero. As previously discussed, $K(y)$ is positive to the south and negative to the north of the area. The plot provides further evidence that stronger (or more frequent) waves are spatially associated with the portion of the AEJ that appears more seasonally unstable. This supports the idea that instantaneous properties of disturbances are somewhat controlled by larger-scale instabilities on a seasonal scale. The concept of wave energy accumulation is used by Done et al. (2010), who demonstrate that "local increase of relative vorticity leads to an increase of tropical cyclogenesis" and that "wave accumulation is consistent with coherent regions in which easterly wind increases towards the east." The spatial relation found here, albeit originating from the analysis of the easterly flow properties, produces a result completely consistent with Done et al. It is important to clarify that no causeeffect relationship is advocated in this work between AEJ instability and TCs since the seasonal instability itself, as computed in the reanalyses, may reflect different causes such as, among others, subgrid precursor triggers. Nonetheless, seasonal shear and instability 
properties of the AEJ appear to allow diagnosis and prediction of TC genesis.

Figure 18 shows the variance of the meridional wind, the genesis points of observed storms, and the area characterized by near-zero $K(y)$ values-all overlaying the mean zonal wind climatology in neutral ENSO years. It is worth observing the areas over the ocean where the variance is a maximum, plotted only within the areas where $K(y)$ is in the range between $-10^{-11}$ and $10^{-11} \mathrm{~m}^{-1} \mathrm{~s}^{-1}$, correspond well with the portion of the eastern Atlantic Ocean where tropical cyclogenesis occurs. In other words, a clear link appears to exist between the 2.5- and 6-day filtered variance of the meridional component of the 700-hPa wind, the satisfaction of barotropic instability condition for the seasonal zonal wind, and the occurrence of observed developments of tropical systems.

\section{Discussion and concluding remarks}

This article starts with an analysis of the AEJ using MERRA data and compares the results with those obtained from other reanalysis datasets, namely, ERA40, JRA-25, and NCEP-R2. The comparison demonstrates the value of MERRA data as a tool for analyzing the African monsoon region and examining those aspects of the African easterly jet that may be relevant to the seasonal prediction problem.

It was shown that, while discrepancies between reanalyses in the representation of the circulation over Africa are getting progressively smaller with respect to previous studies (i.e., Cook 1999), some differences still exist, and these differences are likely due to insufficient data coverage combined with differences in the response of different model physics in the absence of data. Despite these small discrepancies in the representation of the AEJ, the reanalyses agree on the fact that the instability properties of the cyclonically sheared flank of the AEJ, computed on a seasonal scale, correspond well with the requirements of individual wave development. This is a hypothesis that needs to be further investigated, but the preliminary results of this study are encouraging and may be important in increasing seasonal forecasting skill.

An assessment of the mean JAS precipitation shows that MERRA produces an overall smaller bias with respect to GPCP compared with other reanalyses (Fig. 5). Soil moisture gradients, a prominent factor controlling the AEJ, are difficult to assess and verify; however, the overall quality of precipitation distribution in the MERRA data appears satisfactory.

A Hilbert-Huang spectral analysis performed on the datasets reveals that two fundamental time scales can be recognized: at 2.5-6 days, consistent with the variability associated with AEWs, and a variability at 6-9 days. The

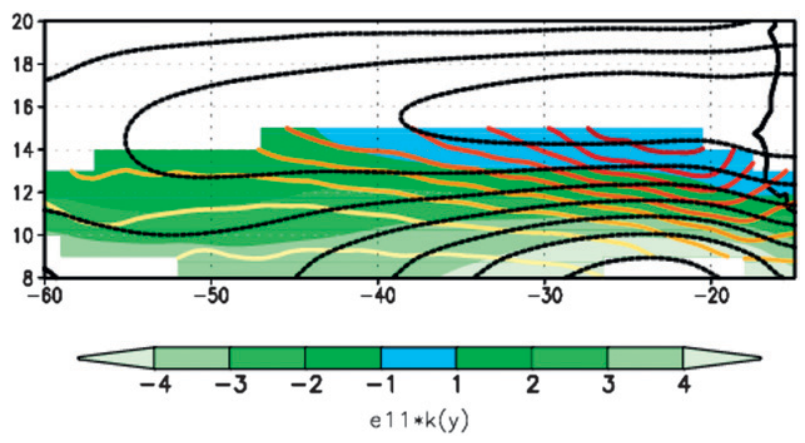

FIG. 17. JAS sum of AEW square intensity climatology $\left(\mathrm{s}^{-2}\right.$, red contours), AEJ climatology ( $\mathrm{m} \mathrm{s}^{-1}$, black contours), and corresponding values of $K$ (shaded). Values in the range $|K|<10^{-11}$ are plotted in blue. Computed for ENSO neutral years.

latter is consistent with a 6-9-day propagation mode discussed by Yanai and Murakami (1970), De Felice et al. (1990), and Diedhiou et al. (1998, 1999). However, this mode of variability did not receive as much attention within the scientific community as the 3-6-day time scales, possibly because of its more elusive signal, which our study suggests to be better captured by using the HilbertHuang transform (Fig. 10), being that this technique is free from the limiting assumptions about oscillatory processes, periodicities, and wave functions required by other methodologies.

In this study we hypothesize that the mode is not purely tropical, as thought by De Felice et al. (1990), because we detect its signal more clearly at more northerly latitudes, in agreement with Diedhiou et al. (1998). Diedhiou et al. (1999) attribute the oscillation to periodic strengthening of the subtropical highs, without searching for a more northern origin. In this article, we speculate, instead, that the 6-9-day mode may arise as a result of a tropicalextratropical interaction. In particular, we note the similarity of the 6-9-day filtered variance of the zonal component of the wind in the levels between 500 and $700 \mathrm{hPa}$ with the typical track of "early recurvers" and the substantial high latitude of the maximum 6-9-day bandpass filtered variance of the meridional component of the wind, reminiscent of the tropical moisture plumes sometimes advected within the southern edge of certain midlatitude disturbances.

These could be symptoms of a larger-scale oscillation, such as the previously observed mode of 6-9 days (Yanai and Murakami 1970). However, the spatial distribution suggests that it may be, instead, an indication of either a subtropical oscillation, a tropical-extratropical connection, or a Rossby wave-possibly arising out of the periodic weakening of the descending branch of the Hadley cell coincident with the transit of midlatitude frontal systems north of $30^{\circ} \mathrm{N}$, which in turn causes a temporary 

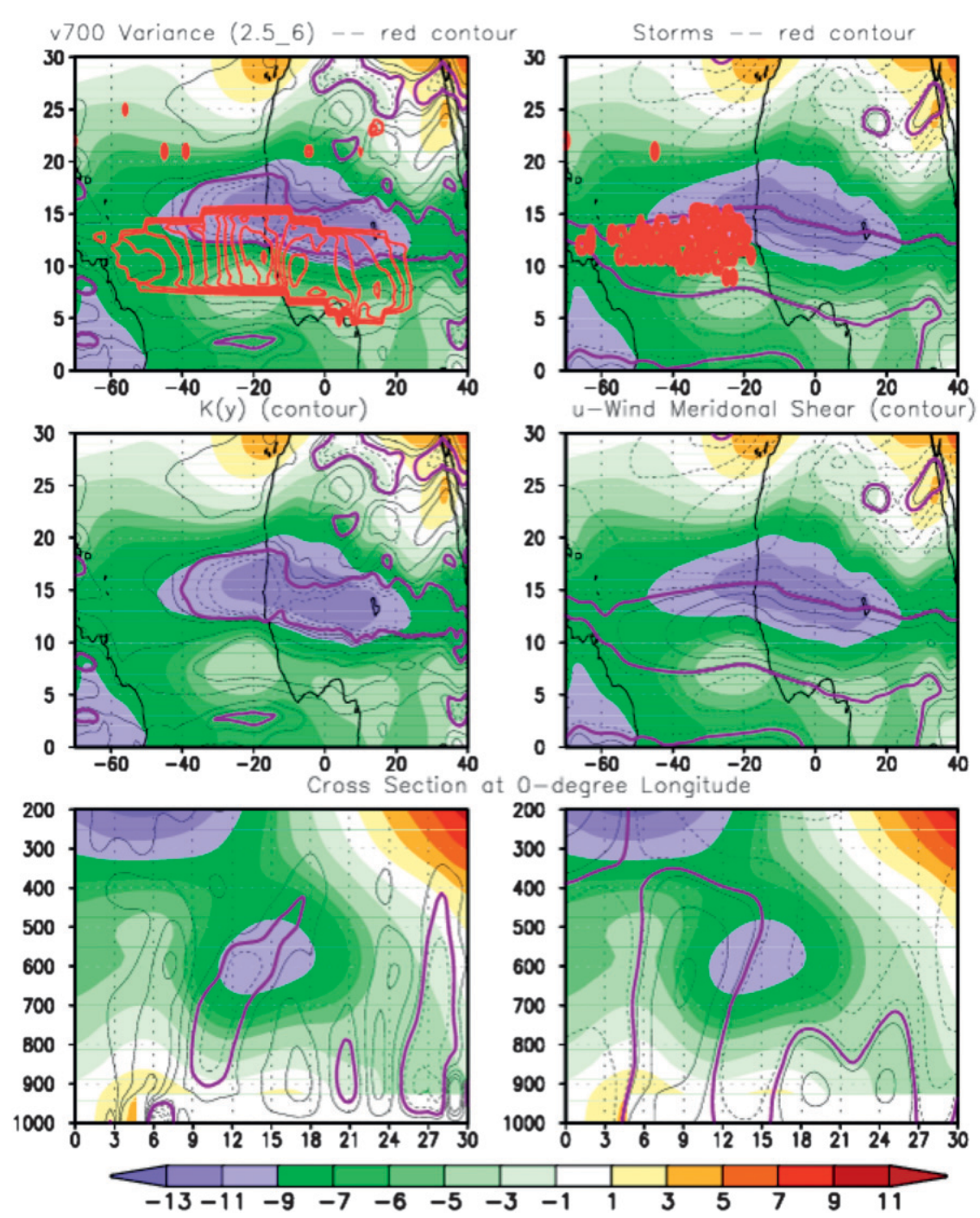

FIG. 18. (top, middle) Zonal wind climatology for JAS, based on MERRA neutral years from 1980 to 2001 ( $\mathrm{m} \mathrm{s}^{-1}$, shaded) and (bottom) vertical cross section at $0^{\circ}$ longitude. Variance of the 6-hourly meridional component of the $700 \mathrm{hPa}$ wind, bandpass filtered through a (left) 2.56-day passband $\left(\mathrm{m}^{2} \mathrm{~s}^{-2}\right.$, red contour) and (right) $-\partial u / \partial y$ (bottom color bar). The variance is plotted only in the areas where the necessary condition for barotropic instability, computed as in Fig. 1 (with $K$ in the range $\pm 10^{-11}$ ), is satisfied. The red shading, upper right panel, indicates observed cyclogenesis.

relaxation of the ITCZ. This allows enhanced southwesterly moist flow advected in the lower midtroposphere (as seen in Turato et al. 2004) from the deep tropics ahead of midlatitude cold fronts and cooler northerly flow in the lowest levels to the rear of them (as documented in Vizy and Cook 2009). It is worth noting that the Diedhiou et al. (1999) explanation of the 6-9-day mode as resulting from the subtropical height strengthening is not inconsistent with the reasoning suggested in this work: if an extratropical system transits north of a subtropical high, a ridging tendency with consequent subtropical high strengthening can be observed ahead of the midlatitude system and a weakening to the rear of it, consequent to cooler northerly low-level flow advection. The 6-9-day periodicity may then coincide with a strengthening (and weakening) of the subtropical anticyclones (as suggested by Diedhiou et al. 1998, 1999), caused by an interaction between tropical and extratropical dynamics, or by a "subtropical oscillation."

In this article it is also found that the necessary condition for barotropic instability computed from the JAS mean zonal wind delineates an area where the variance of the bandpass-filtered (in the 2.5-6-day window) meridional component of the wind has a strong maximum. 
The maximum also corresponds well with the bandpassfiltered precipitation variance maximum (Fig. 12), consistent with the fact that increased variance of the meridional wind component indicates increased wave activity or increased convection.

Finally, the same area where the necessary condition for barotropic instability is satisfied is also the area where, during ENSO neutral years, observed formation of tropical storms occurs (Fig. 18). This is significant because the actual process that can transform an AEW into a closed circulation is described in much more complicated terms by a combination of barotropic and baroclinic instabilities of the Charney-Stern kind (e.g., Thorncroft and Hoskins 1994a; Hsieh and Cook 2005). Additional degrees of complexity are introduced by thermal vertical structure (Thorncroft et al. 2008), convection, vorticity, and moisture distribution (e.g., Hopsch et al. 2010) and with the crucial contribution of other factors such as sea surface temperature, vertical shear, and Saharan air intrusions. However, the key result of this work is that barotropic instability alone, when computed from the seasonal mean zonal wind, appears to strongly constrain the locations where storms occur. Further investigation on the interannual variability is needed: however, if this preliminary finding is confirmed by future studies, this result appears as a potential predictor of TC genesis on a seasonal scale.

In conclusion, there are two major findings that arise from this study.

- The verification of the Kuo barotropic instability condition and $K(y)<0$, computed from the mean JAS zonal wind, has a physical meaning because it outlines very well the areas where storm genesis occurs. We acknowledge the impossibility of separating the vorticity created by moist convection. Nevertheless, it appears to be true that the mean stability properties of the flow constrain the storm genesis points.

- A Hilbert-Huang spectral analysis reveals two prominent modes of variability: one at 2.5-6 days, which corresponds to AEWs, and the other at 6-9 days, which appears to be connected with tropical-extratropical interactions or with a subtropical oscillation. The nature of the 6-9-day mode is the subject of a future article.

Finally, this paper acknowledges the overall complexity of extended-range tropical forecasting in the Atlantic; however, it suggests a direction in which efforts could go, by connecting the stability properties of the monthlymean flow with tropical cyclogenesis and by suggesting a stratified approach that separates ENSO neutral years (examined in this paper) from the ENSO positive or negative years. An extended treatment of the ENSO signal on Atlantic tropical cyclognesis will be the subject of a subsequent article.
Acknowledgments. This work was supported by the NASA Earth Science Enterprise's Global Modeling and Analysis Program. We thank the two anonymous reviewers for their helpful comments.

\section{REFERENCES}

Adler, R. F., and Coauthors, 2003: The Version 2 Global Precipitation Climatology Project (GPCP) monthly precipitation analysis (1979-present). J. Hydrometeor., 4, 1147-1167.

Agusti-Panareda, A., A. Beljaars, C. Cardinali, I. Genkova, and C. Thorncroft, 2010: Impacts of assimilating AMMA soundings on ECMWF analyses and forecasts. Wea. Forecasting, 25, $1142-1160$

Aiyyer, A., and C. D. Thorncroft, 2006: Climatology of vertical wind shear over the tropical Atlantic. J. Climate, 19, 2969-2983.

Arnault, J., and F. Roux, 2009: Case study of a developing African easterly wave during NAMMA: An energetic point of view. J. Atmos. Sci., 66, 2991-3020.

Asnani, G. C., 2005: Tropical Meteorology. 2nd rev. ed., Vols. 1-3, Indian Institute of Tropical Meteorology, $2241 \mathrm{pp}$.

Bosilovich, M. G., and Coauthors, 2006: NASA's Modern Era Retrospective-Analysis for Research and Applications. Variations, No. 4, U.S. CLIVAR, Washington, DC, 5-8.

— Analysis for Research and Applications: Integrating earth observations. [Available online at http://www.earthzine.org/2008/09/ 26/nasas-modern-era-retrospective-analysis.]

Cook, K., 1999: Generation of the African easterly jet and its role in determining West African precipitation. J. Climate, 12, 11651184.

De Felice, P., A. Viltard, D. Monkam, and C. Ouss, 1990: Characteristics of North African 6-9 day waves during summer 1981. Mon. Wea. Rev., 118, 2624-2633.

_ _ _ a and J. Oubuih, 1993: A synoptic-scale wave of 6-9-day period in the Atlantic tropical troposphere during summer 1981. Mon. Wea. Rev., 121, 1291-1298.

Diedhiou, A., S. Janicot, A. Viltard, and P. de Felice, 1998: Evidence of two regimes of easterly waves over West Africa and the tropical Atlantic. Geophys. Res. Lett., 25, 2805-2808.

,,,$--- \ldots$, and H. Laurent, 1999: Easterly wave regimes and associated convection over West Africa and tropical Atlantic: Results from the NCEP/NCAR and ECMWF reanalyses. Climate Dyn., 15, 795-822.

Done, J. M., G. J. Holland, and P. J. Webster, 2010: The role of wave energy accumulation in tropical cyclogenesis over the tropical North Atlantic. Climate Dyn., 36, 753-767.

Ferreira, R. N., and W. H. Schubert, 1997: Barotropic aspects of ITCZ breakdown. J. Atmos. Sci., 54, 261-285.

Goldenberg, S. B., and L. J. Shapiro, 1996: Physical mechanisms for the association of El Niño and West African rainfall with Atlantic major hurricane activity. J. Climate, 9, 1169-1187.

Hall, N. M. J., G. N. Kiladis, and C. D. Thorncroft, 2006: Threedimensional structure and dynamics of African easterly waves. Part II: Dynamical modes. J. Atmos. Sci., 63, 2231-2245.

Hopsch, S. B., C. D. Thorncroft, K. Hodge, and A. Aiyyer, 2007: West African storm tracks and their relationship to Atlantic tropical cyclones. J. Climate, 20, 2468-2483.

,-- , and K. R. Tyle, 2010: Analysis of African easterly wave structures and their role in influencing tropical cyclogenesis. Mon. Wea. Rev., 138, 1399-1419. 
Hsieh, J.-S., and K. Cook, 2005: Generation of African easterly wave disturbances: Relationship to the African easterly jet. Mon. Wea. Rev., 133, 1311-1327.

— , and — 2008: On the instability of the African easterly jet and the generation of African waves: Reversal of the potential vorticity gradient. J. Atmos. Sci., 65, 2130-2151.

Huang, N. E., and S. S. P. Shen, Eds., 2005: Hilbert-Huang Transform and its Applications. Interdisciplinary Mathematical Sciences Series, Vol. 5, World Scientific, 311 pp.

_ Z Z. Shen, and S. R. Long, 1999: A new review of nonlinear water waves: The Hilbert spectrum. Annu. Rev. Fluid Mech., 31, 417-457.

— the Hilbert spectrum for nonlinear and non-stationary time series analysis. Proc. Roy. Soc. London, 454A, 903-995.

Janicot, S., F. Mounier, S. Gervois, B. Sultan, and G. Kiladis, 2010: The dynamics of the West African monsoon. Part V: The detection and role of the dominant modes of convectively coupled equatorial Rossby waves. J. Climate, 23, 4005-4024.

Kanamitsu, M., W. Ebisuzaki, J. Woollen, S.-K. Yang, J. J. Hnilo, M. Fiorino, and G. L. Potter, 2002: NCEP-DOE AMIP-II Reanalysis (R-2). Bull. Amer. Meteor. Soc., 83, 1631-1643.

Kiladis, G. N., C. D. Thorncroft, and N. M. J. Hall, 2006: Threedimensional structure and dynamics of African easterly waves. Part I: Observations. J. Atmos. Sci., 63, 2212-2230.

Kistler, R., and Coauthors, 2001: The NCEP-NCAR 50-Year Reanalysis: Monthly means CD-ROM and documentation. Bull. Amer. Meteor. Soc., 82, 247-267.

Klotzbach, P. J., 2010: On the Madden-Julian Oscillation-Atlantic hurricane relationship. J. Climate, 23, 282-293.

Kossin, J., S. J. Camargo, and M. Sitkowski, 2010: Climate modulation of North Atlantic hurricane tracks. J. Climate, 23, 3057-3076.

Krichak, S. O., P. Alpert, and M. Dayan, 2004: The role of atmospheric processes associated with Hurricane Olga in the December 2001 floods in Israel. J. Hydrometeor., 5, 1259-1270.

Kuo, H.-L., 1949: Dynamic instability of two-dimensional nondivergent flow in a barotropic atmosphere. J. Meteor., 6, 105-122.

Leroux, S., and N. M. J. Hall, 2009: On the relationship between African easterly waves and the African easterly jet. J. Atmos. Sci., 66, 2303-2316.

Leroy, A., and M. C. Wheeler, 2008: Statistical prediction of weekly tropical cyclone activity in the Southern Hemisphere. Mon. Wea. Rev., 136, 3637-3654.

Madden, R. A., and P. R. Julian, 1971: Detection of a 40-50 day oscillation in the zonal wind in the tropical Pacific. J. Atmos. Sci., 28, 702-708.

— the tropics with a 40-50 day period. J. Atmos. Sci., 29, 1109-1123.

Mekonnen, A., C. D. Thorncroft, and A. R. Aiyyer, 2006: Analysis of convection and its association with African easterly waves. J. Climate, 19, 5405-5421.

Mounier, F., S. Janicot, and G. N. Kiladis, 2008: The West African monsoon dynamics. Part III: The quasi-biweekly zonal dipole. J. Climate, 21, 1911-1928.
Onogi, K., and Coauthors, 2007: The JRA-25 Reanalysis. J. Meteor. Soc. Japan, 85, 369-432.

Oppenheim, A. V., and R. W. Schafer, 1975: Digital Signal Processing. Prentice-Hall, 585 pp.

Parker, D. J., and Coauthors, 2008: The AMMA radiosonde program and its implications for the future of atmospheric monitoring over Africa. Bull. Amer. Meteor. Soc., 89, 1015-1027.

Reale, O., L. Feudale, and B. Turato, 2001: Evaporative moisture sources during a sequence of floods in the Mediterranean region. Geophys. Res. Lett., 28, 2085-2088.

Rienecker, M. M., and Coauthors, 2008: The GEOS-5 Data Assimilation System-Documentation of versions 5.0.1, 5.1.0 and 5.20. NASA Tech. Rep. Series on Global Modeling and Data Assimilation, NASA/TM-2008-104606, Vol. 27, 102 pp. [Available online at http://gmao.gsfc.nasa.gov/pubs/tm/.]

Shapiro, L. J., 1977: Tropical storm formation from easterly waves: A criterion for development. J. Atmos. Sci., 34, 1007-1021.

__ , and S. B. Goldenberg, 1998: Atlantic sea surface temperatures and tropical cyclone formation. J. Climate, 11, 578590.

Thorncroft, C. D., and B. J. Hoskins, 1994a: An idealized study of African easterly waves. Part I: A linear view. Quart. J. Roy. Meteor. Soc., 120, 953-982.

— waves. Part II: A non-linear view. Quart. J. Roy. Meteor. Soc., 120, 983-1015.

, and M. Blackburn, 1999: Maintenance of the African easterly jet. Quart. J. Roy. Meteor. Soc., 125, 763-786.

_ J. Hall, and G. N. Kiladis, 2008: Three-dimensional structure and dynamics of African easterly waves. Part III: Genesis. J. Atmos. Sci., 65, 3596-3607.

Turato, B., O. Reale, and F. Siccardi, 2004: Water vapor sources of the October 2000 Piedmont flood. J. Hydrometeor., 5, 693712.

Uppala, S. M., and Coauthors, 2005: The ERA-40 Re-Analysis. Quart. J. Roy. Meteor. Soc., 131, 2961-3012.

Vizy, E. K., and K. H. Cook, 2009: A mechanism for African monsoon breaks: Mediterranean cold air surges. J. Geophys. Res., 114, D01104, doi:10.1029/2008JD010654.

Wheeler, M. C., and H. H. Hendon, 2004: An all-season multivariate MJO index: Development of an index for monitoring and prediction. Mon. Wea. Rev., 132, 1917-1932.

Wu, M.-L. C., S. D. Schubert, and N. E. Huang, 1999: The development of the South Asian summer monsoon and the intraseasonal oscillation. J. Climate, 12, 2054-2075.

—, O. Reale, S. D. Schubert, M. J. Suarez, R. D. Koster, P. J. Pegion, 2009a: African easterly jet: Structure and maintenance. J. Climate, 22, 4459-4480.

- S. D. Schubert, and N. E. Huang, 2009b: An analysis of moisture fluxes into the Gulf of California. J. Climate, 22, 2216-2239.

Yanai, M., and M. Murakami, 1970: Spectrum analysis of symmetric and anti-symmetric equatorial waves. J. Meteor. Soc. Japan, 48, 331-346. 